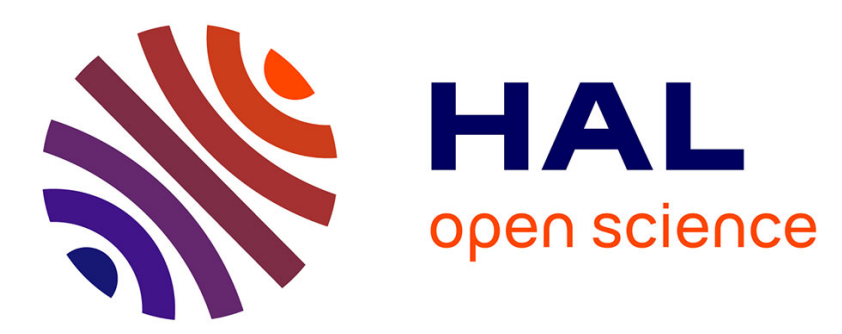

\title{
Thermal expansion of liquid Fe-S alloy at high pressure
} F. Xu, G. Morard, N. Guignot, A. Rivoldini, Geeth Manthilake, J. Chantel, L. Xie, A. Yoneda, A. King, E. Boulard, et al.

\section{To cite this version:}

F. Xu, G. Morard, N. Guignot, A. Rivoldini, Geeth Manthilake, et al.. Thermal expansion of liquid Fe-S alloy at high pressure. Earth and Planetary Science Letters, 2021, 563, pp.116884. 10.1016/j.epsl.2021.116884 . hal-03184365

\section{HAL Id: hal-03184365 \\ https://hal.uca.fr/hal-03184365}

Submitted on 31 Mar 2021

HAL is a multi-disciplinary open access archive for the deposit and dissemination of scientific research documents, whether they are published or not. The documents may come from teaching and research institutions in France or abroad, or from public or private research centers.
L'archive ouverte pluridisciplinaire HAL, est destinée au dépôt et à la diffusion de documents scientifiques de niveau recherche, publiés ou non, émanant des établissements d'enseignement et de recherche français ou étrangers, des laboratoires publics ou privés. 
F. Xu ${ }^{\mathrm{a}}$, G. Morard ${ }^{\mathrm{a}, \mathrm{b}}$, N. Guignot ${ }^{\mathrm{c}}$, A. Rivoldini ${ }^{\mathrm{d}}$, G. Manthilake $^{\mathrm{e}}$, J.Chantel $^{\mathrm{f}}$, L. Xie $^{\mathrm{g}, 1}$,

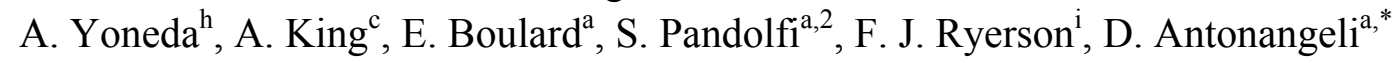

${ }^{a}$ Sorbonne Université, Muséum National d'Histoire Naturelle, UMR CNRS 7590, Institut de Minéralogie, de Physique des Matériaux et de Cosmochimie, IMPMC, 75005 Paris, France

${ }^{\mathrm{b}}$ Université Grenoble Alpes, Université Savoie Mont Blanc, CNRS, IRD, Université Gustave Eiffel, ISTerre, 38000 Grenoble, France

c Synchrotron SOLEIL, L'Orme de Merisiers, Saint Aubin-BP48, 91192 Gif-sur-Yvette, France

${ }^{\mathrm{d}}$ Royal Observatory of Belgium, Avenue Circulaire 3, B-1180 Brussels, Belgium

${ }^{\mathrm{e}}$ Laboratoire Magmas et Volcans CNRS, IRD, OPGC, Université Clermont Auvergne, 63000 Clermont-Ferrand, France

${ }^{\mathrm{f}}$ Univ. Lille, CNRS, INRAE, Centrale Lille, UMR 8207 - UMET - Unité Matériaux et Transformations, F-59000 Lille, France

${ }^{\mathrm{g}}$ Institute for Planetary Materials, Okayama University, Misasa, Tottori 682-0193, Japan

${ }^{\mathrm{h}}$ Department of Earth and Space Science, Graduate School for Science, Osaka University, Toyonaka, Osaka 560-0043, Japan

${ }^{\mathrm{i}}$ Lawrence Livermore National Laboratory, 7000 East Avenue, Livermore, California 94550-9698, U.S.A

${ }^{1}$ Currently at Bayerisches Geoinstitut, Universität Bayreuth, 95440 Bayreuth, Germany

${ }^{2}$ Currently at Fundamental Physics Directorate, SLAC National Accelerator Laboratory, Menlo Park, CA, United States 


\title{
Highlights
}

- Density of liquid Fe-S alloys has been measured under high pressure as a function of temperature by in situ X-ray diffraction in multi-anvil press.

- Thermal expansion of liquid Fe-S alloys has been determined up to $7 \mathrm{GPa}$ and 2200 K.

- Top-down crystallization is the most likely scenario for Fe-FeS cores of planetesimals and small planets.

\begin{abstract}
Local structure and density of liquid Fe-S alloys at high pressure have been determined in situ by combined angle and energy dispersive X-ray diffraction experiments in a multi-anvil apparatus, covering a large temperature and compositional range. Precise density measurements collected for increasing temperature allowed us to directly derive the thermal expansion coefficients for liquid $\mathrm{Fe}-\mathrm{S}$ alloys as a function of composition. In turn, thermal expansion has been used to refine thermodynamic models and to address the crystallization regime of telluric planetary cores by comparing the adiabatic temperature gradient and the slope of the liquidus in the Fe-FeS system.

For Fe-S cores of asteroids and small planetesimals, top-down solidification is the dominant scenario as the compositional domain for which the slope of the liquidus is greater than the adiabatic gradient is limited to a narrow portion on the Fe-rich side. However, bottom-up growth of the inner core is expected for S-poor cases, with this compositional domain expanding to more S-rich compositions with increasing pressure (size of the planetary body). In particular, bottom-up crystallization cannot be excluded for the Moon and Ganymede.
\end{abstract}




\section{Introduction}

Many recent studies highlight a rich diversity in the core structure of terrestrial bodies, largely depending on the core crystallization regime (e.g. Breuer et al., 2015; Dumberry and Rivoldini, 2015; Hauck et al., 2006; Rivoldini et al., 2011; Rückriemen et al., 2018, 2015; Williams, 2009). This, in turn, directly depends on pressure conditions and light element content, which relates to accreting material, planetary differentiation process and planet's size. From an observational point of view, indications on the core structure and dynamics can be derived from geodetic data (static and dynamic gravity field, and rotation) and, when present, from the magnetic field. The presence of an internally generated magnetic field is relatively common in the terrestrial bodies of our solar system. Aside from Earth, active global magnetic fields of internal origin have been detected on Mercury and Ganymede (Kivelson et al., 1997; Ness, 1979). A strong, though now extinct, magnetic field was also present on Mars, as suggested by crustal magnetic field maps (e.g. Acuña et al., 1999, 2001; Connerney et al., 2001) and on the Moon, as evidenced from the remnant magnetism of the lunar crust (e.g. Weiss and Tikoo, 2014). Furthermore, magnetized meteorites indicate that planetesimals and numerous planetary bodies may have had their own self-generated, long-lived fields (e.g. Weiss et al., 2008; Shah et al., 2017; Bryson et al., 2019a). A dynamo operating in the fluid metallic core is the most likely mechanism for generating a planetary magnetic field, and compositional convection driven by core solidification is one of the main power sources for a long standing dynamo (Stevenson, 2003). The strength and lifetime of a magnetic field is thus directly tied to the crystallization process of the core, which can proceed very differently in various planets, depending on composition and size (e.g. Breuer et al., 2015; Rückriemen et al., 2018).

As a first order guidance, neglecting complexities arising because of nucleation barriers (e.g. Davies et al., 2019; Huguet et al., 2018), we here assume that solid inner core starts to form when the temperature drops below the melting curve of the core-forming material (the liquidus). In a convecting medium the temperature profile is almost isentropic and the core temperature is generally assumed to follow an adiabat. The relative slopes $(\mathrm{dT} / \mathrm{dP})$ of the adiabat and of the liquidus thus determine the style of core solidification (e.g. Breuer et al., 2015; Williams, 2009). If the adiabat is shallower than the liquidus, crystallization occurs at depth, as for the Earth, and the inner core grows bottom-up. On the contrary, if the adiabat is steeper than the liquidus, top-down solidification is expected, in which shallow crystallization occurs and solid material sinks or floats, depending upon density contrast with the liquid, leading to possible compositional stratification (e.g. Dumberry and Rivoldini, 2015; Hauck et al., 2006; Rückriemen et al., 2018, 2015). Although both scenarios don't rule out the development of a dynamo, how and when a magnetic field can be generated in the course of top-down crystallization remains debated (e.g. Breuer et al., 2015).

Sulfur (S) is classically considered to be the major light element alloyed to iron $(\mathrm{Fe})$ in the core of small planetary bodies (e.g. Antonangeli et al., 2015; Breuer et al., 2007; Morard et al., 2018; Terasaki et al., 2019; Rückriemen et al., 2015; Weber et al., 2011). The actual S content depends on primordial composition of the planetary forming material and the partitioning of sulfur between silicate and metallic phases, which in turn depends on 
temperature and pressure conditions, as well as on the oxidation state, during core formation. For instance, while both Mercury and Mars are thought to have significant $\mathrm{S}$ in their bulk composition, the greater distance from the Sun and the more oxidizing formation conditions support more significant enrichment of $\mathrm{S}$ in the core of Mars than in that of Mercury (Dumberry and Rivoldini, 2015; Hauck et al., 2006; Rivoldini et al., 2011). Ultimately differences in the $\mathrm{P}, \mathrm{T}, \mathrm{fO}_{2}$ conditions of core formation result in a large variation in the $\mathrm{S}$ abundance in the liquid cores of planets and moons. For instance, S content in the Moon's core is classically limited to less than 8 wt.\% (e.g. Antonangeli et al., 2015; Laneuville et al., 2014; Rai and Van Westrenen, 2014; Steenstra et al., 2017), while in the case of the Jovian moons Ganymede and Callisto, the core might have a $\mathrm{S}$ concentration greater than the eutectic concentration (e.g. Scott et al., 2002). As a direct consequence of this composition diversity, different crystallization scenarios can arise. Indeed S content significantly affects the difference in the adiabat vs. liquidus relations and density contrast between the crystallizing solid and the liquid phases (e.g. Breuer et al., 2015; Williams, 2009).

Thermal expansion is a central parameter controlling the slope of the adiabat (Stacey, 2005; Williams, 2009), which can be written as

$$
\mathrm{dT} / \mathrm{dP}=\alpha(\mathrm{P}) \mathrm{T} / \rho(\mathrm{P}) C_{\mathrm{P}}
$$

where $\alpha(\mathrm{P})$ is the pressure-dependent thermal expansion, $T$ the temperature at which the adiabatic gradient is calculated, $\rho(\mathrm{P})$ the pressure-dependent density, and $C_{\mathrm{P}}$ the heat capacity at constant pressure.

According to its definition, thermal expansion can be experimentally derived from the variation of the density with the temperature (at constant pressure)

$$
\alpha(\mathrm{P}, \mathrm{T})=-1 / \quad \rho(\mathrm{P}, \mathrm{T})(\mathrm{d} \rho(\mathrm{P}) / \mathrm{dT})
$$

Due to the experimental difficulties in density measurement, neither thermal expansion measurements over a wide compositional range $(0-50$ at $\% \mathrm{~S})$ nor under high pressure have been performed. Thermal expansion of liquids in the Fe-FeS system has been studied exclusively at ambient pressure and only for end-member liquids, Fe and FeS (e.g. Assael et al., 2006; Kaiura and Toguri, 1979; Nagamori, 1969). Results on FeS (Kaiura and Toguri, $1979)$ are limited to few points covering a very limited T range ( 1500-1650 K). Even in the case of liquid $\mathrm{Fe}$, in spite of the large number of studies, proposed values for thermal expansion show large discrepancies (e.g.; $11.0 \times 10^{-5} \mathrm{~K}^{-1}$, Hixson et al., $1990 ; 8.2 \times 10^{-5} \mathrm{~K}^{-1}$, Nasch and Steinemann, $1995 ; 13.2 \times 10^{-5} \mathrm{~K}^{-1}$, Assael et al., 2006). Density determinations of liquid Fe-S alloys under high pressure includes ex-situ sink-float (Balog et al., 2003; Nishida et al., 2008), X-ray absorption (Chen et al., 2014; Nishida et al., 2011; Sanloup et al., 2000; Terasaki et al., 2019) and X-ray diffraction (Morard et al., 2018) methods. However, none of these methods provided sufficient temperature-dependent density data to allow precise determination of thermal expansion, due to combined difficulties in density measurements and temperature control at high pressure.

As highlighted by Williams (2009), extrapolation of thermal expansion of liquid Fe and FeS to pressures, temperatures and compositions directly relevant for planetary cores comes 
with significant uncertainties that limit the reliability of the assessment of the relative slopes of the adiabats and liquidus curves (which also is not so well known). The determination of thermal expansion of liquid Fe-S alloys under the high-pressure conditions existing in planetary cores is thus of fundamental importance for refining thermodynamic models of planetary cores (Morard et al., 2018; Rivoldini et al., 2011; Terasaki et al., 2019) and to constrain adiabatic heat flux in cores of telluric bodies (Silber et al., 2018).

In this study, we provide direct determinations of the thermal expansion of liquid Fe-S alloys in the 4 to $9 \mathrm{GPa}$ range, pressures directly relevant for the core of the Moon and Ganymede, using a combined angular and energy dispersive X-ray diffraction (CAESAR) technique (Wang et al., 2004). X-ray diffuse scattering from a liquid sample was analyzed to extract local structure information and also used to determine liquid density at high pressure (Eggert et al., 2002; Morard et al., 2014). To date, this method has been applied in Paris-Edinburgh (PE) cell and diamond anvil cell (DAC) for structural and density studies of liquids under high pressure (e.g. Morard et al., 2018, 2017, 2014; Sanloup et al., 2013; Yamada et al., 2011, 2007). Here we present the nontrivial extension of these measurements to the multi-anvil press. Noticeably, extension of this methodology to the multi-anvil press enables investigations over larger pressure range than achievable in PE experiments and, more importantly, the ability to vary the temperature of a confined liquid with the precision needed for the determination of thermal expansion, refinements not possible in the above-mentioned early PE and DAC studies. Measured thermal expansions are used together with thermodynamic modeling to assess the pressure and compositional dependence of the adiabatic gradients in the liquid $\mathrm{Fe}-\mathrm{FeS}$ system in the 0 to $10 \mathrm{GPa}$ range and, by comparison with the slope of the liquidus, to discuss the crystallization regime in the cores of small planetary bodies, encompassing conditions of the Moon and Ganymede.

\section{3}

\section{Methods}

\subsection{In-situ CAESAR measurement under high pressure in a multi-anvil press}

High-pressure experiments were carried out in situ in the DIA-type multi-anvil apparatus installed on the beamline PSICHE of SOLEIL, France. Starting materials with final compositions of 5, 10, 15, 20, 25 and 36.4 wt.\% S, corresponding to 8.4, 16.3, 23.6, 30.4, 36.8 and 50 at.\%, respectively, were obtained by a dry homogenization of mixtures of Fe and FeS powders in a mortar (without lubricants such as ethanol or acetone). The prepared mixtures were stored in a portable vacuum box to minimize the moisture absorption from air, and kept there until loading right before the experiment. For the high P-T experiments samples were placed in sapphire capsule capped with BN. The pressure assembly consisted of $26 \mathrm{~mm}$ WC cubes with $4 \mathrm{~mm}$ truncation and and pressure was measured in situ using the known equation of state of the $\mathrm{MgO}$ marker (Tange et al., 2009). Schematic view of the cell assembly is shown in Fig. S1. Trimmed octahedral pressure medium made from $\mathrm{B}+15 \mathrm{wt} . \%$ $\mathrm{MgO}$ (B85) was employed to minimize the absorption and diffraction of the sample environment (Xie et al., 2020). B85 gaskets were also used along the X-ray path instead of pyrophyllite gaskets. To remove the water absorbed during fabrication prior to the 
experiment, $\mathrm{MgO}$ and $\mathrm{ZrO}_{2}$ parts were baked at $1273 \mathrm{~K}$ for 1 hour; $\mathrm{BN}$, graphite and $\mathrm{B} 85$ were kept at $393 \mathrm{~K}$ in a vacuum oven for more than 12 hours. Such a tailored cell assembly was proven to be fundamental to the collection of high-quality CEASAR data. High temperature was generated with graphite heaters and monitored with a $W_{97} R_{3}-W_{75} R_{25}$ thermocouple whose junction was set at the position symmetrical to the sample capsule with respect to the center of furnace. Status of cell assembly during the experiments was monitored by X-ray radiography.

Energy dispersive X-ray diffraction (EDD) measurements were carried out using a polychromatic X-ray (20-100 keV) focused to $25 \mu \mathrm{m}$ vertically (FWHM) and collimated to $50 \mu \mathrm{m}$ horizontally, much smaller than the sample dimension $(0.8 \mathrm{~mm}$ diameter, $0.5 \mathrm{~mm}$ thick, Fig. S1). A Canberra SSD Ge detector associated with a XIA multi-channel analyzer with 2048 energy bins was used to acquire EDD covering energies up to $102.4 \mathrm{keV}$. The energies were calibrated using characteristic fluorescence X-ray lines of Mo, Sn, Ba, Sm and $\mathrm{Au}$. The $2 \theta$ angle was calibrated from 5 to $25^{\circ}$ using a $7 \mu \mathrm{m}$ thick Au foil with a precision of $\pm 0.003^{\circ}$.

For all runs, the specimen was first brought to the target pressure and then heated to high temperature while collecting energy dispersive diffraction patterns at a fixed angle $\left(8^{\circ}\right)$. The melting of sample was identified from the disappearance of sharp diffraction peaks during temperature increase, and confirmed by the absence of any sharp peak during CAESAR acquisition. Once complete melting was achieved, CAESAR spectra were collected in order to obtain the structural and density information of the liquid. CAESAR collections were then repeated for increasing temperature, with 100-200 K steps. For each CAESAR scan, EDD were collected every $0.2^{\circ}$ over a $2 \theta$ angle ranging from 2.5 to $24.1^{\circ}$, allowing acquisition of high quality raw data over a wide $Q$-range, up to $15 \mathrm{~A}^{\circ-1}(Q=4 \pi E \sin \theta / 12.398$, where $E$ is the energy of the X-rays in $\mathrm{keV})$. All measured EDD are combined to form a two-dimensional array of intensities, $\operatorname{Int}(E, 2 \theta)$, with each Int value corresponding to a given $\mathrm{E}$ and $2 \theta$ index. Fig. 1a shows representative raw data collected on $\mathrm{Fe}-\mathrm{S}$ in this study. CAESAR scan with good counting statistics were acquired with collection times of $5 \mathrm{sec}$ for EDD between 2.5 and $10^{\circ}, 10 \mathrm{sec}$ for EDD between 10 and $20^{\circ}$ and $20 \mathrm{sec}$ for EDD between 20 and $24.1^{\circ}$ (about 25 minutes in total). The horizontal gaps of the collimating slits were opened gradually during the angular scan from low angle to high angle to control the effective sample volume from which the diffracted X-rays was detected for discriminating sample signal from background scattering caused by surrounding materials. The raw CAESAR data were normalized by collection time and effective sample volume for further treatment. To improve counting statics, raw data were binned utilizing energy data following the method described in Wang et al. (2004) (Fig. 1b).

In view of the vertical focusing of the beam, 2D radiographies for alignment and sample observation purposes were recorded by scanning the press in front of the beam (scanning radiography) (Fig. 1c, d).

\subsection{Analysis of the recovered samples}

After experiments, the recovered cells were mounted in epoxy resin and polished along 
using diamond abrasive disks with $120,30 \mu \mathrm{m}$ and diamond paste with $1 \mu \mathrm{m}$ grain size to obtain well-polished surface. Microstructure of recovered samples was analyzed by a field emission scanning electron microscope (SEM-FEG) (Zeiss Ultra55) at IMPMC, Sorbonne Université, France. The Fe and $\mathrm{S}$ contents and the concentrations of potential contaminants $(\mathrm{B}, \mathrm{N}, \mathrm{C}, \mathrm{Al}, \mathrm{O}, \mathrm{W}, \mathrm{Re}$ ) were determined using electron probe microanalyses (EPMA) at Centre Camparis, Sorbonne Université, France using a Cameca SX-FIVE wavelength dispersive spectrometer (WDS) operating at $15 \mathrm{kV}$ and $300 \mathrm{nA}$. Our recovered samples show fine dendritic textures of $\mathrm{Fe}$ and $\mathrm{Fe}-\mathrm{S}$; we therefore used a defocused beam of $\sim 30 \mu \mathrm{m}$ to average the compositions of the quenched liquid. Bulk chemical compositions were obtained by averaging 5-10 measurements. Table 1 reports the obtained average values and corresponding standard deviations.

\subsection{Analysis of diffuse scattering signal}

The scattering intensity curve, $I(Q)$, is constructed by merging the normalized EDD and removing the background (taking advantage of data collected at multiple $2 \theta$ angles over overlapping $Q$ range (Fig. 2a)). The structure factor, $S(\mathrm{Q})$, and the pair distribution function, $g(r)$, are calculated for the fixed $Q$ range of 1-10 $\AA^{-1}$ for all cases. The structure factor, $S(Q)$, is first obtained after subtraction of incoherent scattering $\left(I_{\text {inc }}(Q)\right)$. The distribution function, $F(r)$, and pair distribution function, $g(r)$, are obtained by the Fourier transformation of structure factor. Following the method detailed in (Morard et al., 2014, 2013), determination of density is based on the assumption that, due to the increasingly strong repulsive component in the interatomic potential, no atoms are located closer than minimal distance, $r_{\text {min }}$. Thus $F(r)=-4 \pi r \rho$ for $r<r_{\min }$. Density is, hence, extracted following the minimization of the oscillation in the short distance of the radial distribution function $g(r)$ (through a merit $\chi^{2}$ ) (Eggert et al., 2002). Fig. 2b illustrates atomic densities calculated for different values of the minimal distance $r_{\min }$ at different temperatures. The value of $\chi^{2}$ exhibits a well-defined minimum in most cases $\left(r_{0}\right.$ in Fig. $2 b$ ), which gives the atomic density $\rho_{0}$ for which the relation $F(r)=-4 \pi r \rho$ is best-satisfied (Fig. 2c). The position of $r_{\min }$ usually corresponds to the base of the first coordination sphere in $g(r)$. Noteworthy for the purpose of the present study, while absolute values of density depend upon $r_{\text {min }}$, density variation with temperature $(\mathrm{d} \rho / \mathrm{dT})$ is effectively independent of $r_{\text {min }}$ (Fig. 2b).

Various aspects of the data treatment enter into the assessment of the error bar on the absolute density value, including the selected $Q$ range, the choice of the minimum distance of the first coordination sphere $\left(r_{0}\right)$, along with physical phenomena neglected here such as the self-absorption from the sample (Morard et al., 2018, 2014). In the present data set, the estimated error is \pm 3 atoms $/ \mathrm{nm}^{3}$ for the atomic density, corresponding to $\pm 220-270 \mathrm{~kg} / \mathrm{m}^{3}$ for the mass density of the Fe-S liquids (depending on composition).

\subsection{Analysis at constant pressure}

For analysis at constant pressure, experimental densities have been rescaled to $7 \mathrm{GPa}$ following a Murnaghan formalism: 


$$
P-P_{\text {ref }}=\frac{K_{r e f}}{K^{\prime}}\left[\left(\frac{\rho}{\rho_{\text {ref }}}\right)^{K^{\prime}}-1\right]
$$

where $P$ is $7 \mathrm{GPa}$ and $\rho$ is the recalculated density at $7 \mathrm{GPa}, P_{\text {ref }}$ and $\rho_{\text {ref }}$ are our direct obtained experimental data at actual temperatures (Table 1), $K_{r e f}$ is the isothermal bulk modulus at $P_{\text {ref }}$ and $1900 \mathrm{~K}$, and $K^{\prime}$ is its pressure derivative. When not otherwise specified, we used the parameterization discussed in (Morard et al., 2018). Both $K_{r e f}$ and $K^{\prime}$ are functions of atomic S content (XS) in the liquid. The isothermal bulk modulus at ambient pressure and $1900 \mathrm{~K}$ of $\mathrm{Fe}-\mathrm{S}$ alloys was obtained following (Chen et al., 2014) according to the relation $K_{0}=K_{\mathrm{Fe}}^{1-X_{S}} * K_{S}^{X_{S}}$, assuming an exponential dependence of the bulk modulus of liquid Fe-S alloys with $\mathrm{S}$ content, and with $K_{\mathrm{Fe}}=76 \mathrm{GPa}$ and $K_{\mathrm{S}}=1.6 \mathrm{GPa}$. The pressure derivative of the bulk modulus $\left(K^{\prime}\right)$ was obtained as $K^{\prime}=K_{\mathrm{Fe}}^{\prime}+X \mathrm{~S} \cdot 3$, with $K_{\mathrm{Fe}}^{\prime}=$ 6.5 (Morard et al., 2018). In this analysis the temperature dependence of bulk modulus was neglected (temperature range of interest $<500 \mathrm{~K}$ ).

\subsection{Thermodynamic models}

To model the thermodynamic properties of liquid Fe-S (for brevity 1-Fe-S) alloys we use the non-ideal solution model introduced in Morard et al. (2018) and Terasaki et al. (2019). The excess mixing volume is assumed to be pressure dependent and parameterized by an asymmetric Margules formulation. The two end-member phases of the binary solution model are 1-Fe and l-FeS. The volume of the non-ideal solution is:

$$
V\left(\chi_{F e S}, P, T\right)=\left(1-\chi_{F e S}\right) V_{F e}(P, T)+\chi_{F e S} V_{F e S}(P, T)+\chi_{F e S}\left(1-\chi_{F e S}\right) V_{e x}\left(\chi_{F e S}, P\right)
$$

where $\chi_{F e S}$ is the mol fraction of FeS, $V_{F e}$ and $V_{F e S}$ are the molar volumes of pure 1-Fe and l-FeS, and $V_{e x}$ is the pressure and composition dependent excess mixing volume given by:

$$
V_{e x}\left(\chi_{F e s}, P\right)=\left(\chi_{F e S} W_{F e}+\left(1-\chi_{F e S}\right) W_{F e S}\right) v(P),
$$

where $v(P)$ is the pressure dependent contribution to the Margules parameters. Differently from Morard et al. (2018) and Terasaki et al. (2019) $v(P)$ is not parameterized by empirical expressions, but with a pseudospinodal equation of state (EOS) (Baonza et al., 1995):

$$
v(P)=\exp \left[\frac{1}{K^{\prime}}\left(1-\sqrt{1+2 \frac{K^{\prime}}{K_{0}} P}\right)\right]
$$

The parameters $W_{F e}, W_{F e S}, K_{0}$, and $K^{\prime}$ and the equation of state parameters of 1-FeS are estimated from the data of this study as well as from density measurements of Morard et al. (2018) and acoustic velocities of Nasch et al. (1994) and Nishida et al. (2016).

$$
\text { Several recently published EOS of 1-Fe (e.g. Komabayashi, 2014; Dorogokupets et al., }
$$


312 the prediction of density and acoustic velocities along isentropes at high pressure and 313 temperature (Fig. S2a). Nonetheless, quantities derived from the associated thermodynamic 314 potentials, such as the thermal expansivity and heat capacity that determine the adiabatic gradient in a convecting liquid core of a planet, show relatively large deviations (Fig. S2b, c). Therefore, the EOS of 1-Fe affects not only the estimation of the temperature in the core but, together with dependent thermodynamic quantities, also determines the locations at which the core temperature drops below the liquidus. For this reason we assess here how the EOS of 1-Fe of Komabayashi (2014), Dorogokupets et al. (2017) and Wagle and Steinle-Neumann (2019) affect the thermodynamic properties predicted by our 1-Fe-S model. In the following we will refer to Model K, Model D and Model W to denote the thermodynamic models constructed on the basis of our datasets in the Fe-S system at high pressure and high temperature, which respectively make use of Komabayashi (2014), Dorogokupets et al. (2017) and Wagle and Steinle-Neumann (2019) for the EOS of 1-Fe.

For the EOS of 1-FeS we use a Vinet equation and the Anderson-Grüneisen formulation to describe the pressure dependence of the thermal expansivity $(\alpha)$ (e.g. Komabayashi, 2014). As we could not estimate $\alpha$ and the value of the Grüneiesen parameter at reference conditions $\left(\mathrm{P}_{\mathrm{ref}}=0.1 \mathrm{MPa}\right.$ and $\left.\mathrm{T}_{\mathrm{ref}}=1650 \mathrm{~K}\right)$ from our experimental data, we assume $\alpha=11.8 \times 10^{-5} 1 / \mathrm{K}$ from Kaiura and Toguri (1979) and the isobaric heat capacity $C_{P}=62.5 \mathrm{~J} / \mathrm{K} / \mathrm{mol}$ (Chase, 1998). The Grüneisen parameter at reference conditions can then be computed from the estimated EOS parameters with the thermodynamic relation

332

$$
\gamma=\frac{K_{T} V \alpha}{C_{P}-K_{T} V T \alpha^{2}}
$$

where $K_{T}$ is the isothermal bulk modulus and $V$ is the molar volume. The EOS parameters and Margules coefficients estimated from the experimental data for the three different models, using different EOS of 1-Fe, are given in Table S1.

The liquidus at sulfur concentration lower than that of the eutectic is parameterized following Buono and Walker (2011) (Eq. 7-9). This procedure neglects the small amount of $\mathrm{S}$ that can be dissolved in solid $\mathrm{Fe}$ and requires only the knowledge of the Gibbs energy of 1-Fe and stable solid Fe phases together with the Margules parameters required to describe the non-ideal behavior of the Fe-S system. To obtain a thermodynamically consistent description we compute the liquidus according to the l-Fe EOS' of Komabayashi 2014 and Dorogokupets et al. 2017 together with the EOS' of the relevant solid phase provided by those authors (Model K and Model D).

Using those EOS' the Margules parameters are then estimated from experimental melting data. Here we make use of the experimental data at 1 bar (e.g. Waldner and Pelton, 2005), $3 \mathrm{GPa}$ (Brett and Bell, 1969), $6 \mathrm{GPa}$ (Buono and Walker, 2011) and $10 \mathrm{GPa}$ (Chen et al., 2008). With the knowledge of the Margules parameters and with the EOS' of 1-Fe and solid $\mathrm{Fe}$, the liquidus can then be computed at the required pressures. The estimated values of the Margules parameters are given in Table S2. 


\section{Results}

The experimental data obtained here are summarized in Table 1 and described more in detail in the following subsections.

\subsection{Recovered sample and chemical compositions}

A representative cross-section of the recovered cell is shown in Fig. 3a. All of the samples (except FeS end member) exhibited homogeneous dendritic textures (Fig. 3c-g), characteristic of completely molten samples. The compositions of the recovered samples determined by EPMA marginally deviate from the starting compositions of the initial powder mixtures, showing a systematic increase by $0.7-1.8$ at.\% in the $\mathrm{S}$ content (Table 1). Potential causes include $\mathrm{Fe}$ exsolution from the liquid as an oxide, or simply a deviation from the expected 1:1 molar ratio in the FeS starting material. Possible chemical contamination by $\mathrm{B}$, $\mathrm{N}, \mathrm{C}, \mathrm{Al}, \mathrm{O}, \mathrm{W}$ and Re was carefully checked. No Al contamination from sapphire capsule was ever observed for any of the samples. Some of the runs on samples with high melting temperature (low S content) showed B and/or N contamination from the BN cap (Fig. S1). For runs for which we experienced a thermocouple failure, often in relation to sample leaking as observed by in-situ radiography, $\mathrm{W}$ and Re were often detected in the analysis of the recovered experiments. In this paper we only present analysis of data from samples that show no contamination.

\subsection{Structure of liquid Fe-S alloys}

Fig. 4 shows examples of the structure factors, $S(Q)$, and derived pair distribution functions, $g(r)$, of liquid Fe-S alloys at high pressure and high temperature. The shape of $g(r)$ is characterized by two peaks located at approximately $2.35-2.55 \AA$ and $4.7 \AA$ corresponding to the distance of the first and second coordination spheres (CS), respectively. The sharpness of these features decrease with increasing $\mathrm{S}$ content, and a third local maximum around $6.5 \AA$ is visible only for alloys with 31.7 at.\% or less (the $g(r)$ become less structured with increasing $\mathrm{S}$ content). The first peak position of $g(r), r_{1}$, was observed to monotonically decrease with increasing S content (Table 1, Fig. S3), which agrees quite well with previous report on liquid Fe-S (Shibazaki and Kono, 2018). The progressive reduction of $r_{1}$ with $\mathrm{S}$ content can be rationalized by considering that the partial pair distribution functions systematically show Fe-S bonds $(\sim 2.2 \AA)$ shorter than Fe-Fe bonds $(\sim 2.5 \AA)$ (Morard et al., 2018). As mentioned, with increasing $\mathrm{S}$ content, the first and second peaks of $S(Q)$ become broader, and oscillation of the $g(r)$ becomes less pronounced (Fig. 4a, b). The second oscillation in the $g(r)$ seems to vanish at 51.2 at.\% S.

For a fixed $\mathrm{S}$ concentration, the $S(Q)$ and $g(r)$ do not show major changes with temperature (Fig. 4c, d). On a qualitative ground, this indicates that the temperature does not significantly modify the structure of liquid Fe-S alloys over the investigated range, other than for the increasing bond length. 


\subsection{Density and thermal expansion of liquid $\mathrm{Fe}-\mathrm{S}$ alloy}

394 All densities determined in this study are reported in Table 1. In selected cases we repeated the measurements in more than one heating cycle (e.g. MA40), showing a remarkable consistency. Also, using the nominal starting composition, the densities derived from data obtained in an experiment with leakage of the molten sample (MA58), yielded values compatible with those from more reliable data (MA66) obtained in the absence of leakage. The systematic consistency of our results proves the validity of our data collection strategy and data treatment (e.g. range of $Q$, value of $r_{\text {min }}$ ). As such, pressure and temperature derivatives of density, as its variation with $\mathrm{S}$ content, are highly reliable (see also discussion in section 2.3).

Previous density data for liquid Fe-S alloys under high pressure includes results obtained by ex-situ sink-float (Balog et al., 2003; Nishida et al., 2008), in situ X-ray absorption (Chen et al., 2014; Nishida et al., 2011; Sanloup et al., 2000; Terasaki et al., 2019) and X-ray diffraction (Morard et al., 2018) methods. The reported values display large discrepancies, however, even when the same method was used. Overall, the derived thermodynamic model from this study is compatible with densities determined here, although the agreement is less good for alloys with moderate S content (18 at.\% or below) (Fig. S4). Of the parameters entering into the density modeling, the weight of thermal expansion is small, in particular when compared to that of compressibility. The most direct way to assess thermal expansion is thus considering the density evolution with increasing temperatures as from equation (2). Density determination for liquid $\mathrm{Fe}-\mathrm{S}$ alloys with different $\mathrm{S}$ content at $7 \mathrm{GPa}$ over an extended temperature range in this study is summarized and compared with thermodynamic Model W (Fig. 5).

For each composition, density decreases approximately linearly with increasing temperature (see section 2.4, equation 2). Aside from the already mentioned difference in the absolute density values noticeable for the alloys with low-S content, the thermodynamic model, is in good agreement with the experimentally observations for all the liquid alloys. Within the scatter of the data, the temperature derivative of the density doesn't show a clear compositional dependence (Fig. S5). As such, we cannot discriminate between results from thermodynamic Model K, Model D and Model W (see section 2.5), which equally well account for the measurements. Similarly, the experimentally derived thermal expansion shows values scattered in the range $6-13 \times 10^{-5} \mathrm{~K}^{-1}$ (Fig. 6), in overall agreement with the results of the three thermodynamic models, but higher than previous models (Morard et al., 2018; Terasaki et al., 2019), in particular for S-rich samples.

To a large extent, the variability in our thermodynamic models reflects the spread in the values of thermal expansion of liquid Fe at ambient pressure (e.g. Williams, 2019). The density of model $\mathrm{W}$ has the strongest dependence on temperature for liquid $\mathrm{Fe}$ at ambient pressure (Fig. S6), with a thermal expansivity $\left(14.1 \times 10^{-5} \mathrm{~K}^{-1}\right.$ at $\left.1900 \mathrm{~K}\right)$ in agreement with Assael et al., (2006), while the thermal expansivity of Model K and Model D are smaller (respectively 9.0 and $9.3 \times 10-5 \mathrm{~K}-1$ at $1900 \mathrm{~K}$ ) and in good agreement with the values of 433 Hixon (1990). 


\section{Discussion}

\subsection{Slope of adiabat and core solidification}

As already mentioned, the dynamic of crystallization in liquid planetary cores can be evaluated by comparing the adiabatic temperature gradient (slope of the isentrope) and the slope of the liquidus, which, in turn, depend upon pressure and chemical composition of the studied cores.

The adiabatic gradient in a liquid core is calculated according to the relation (1) for the three thermodynamic models, with densities benchmarked against measurements. Specific to liquid FeS, we use $C_{P}=62.5 \mathrm{~J} / \mathrm{K} / \mathrm{mol}$ from NIST at 1bar (Chase, 1998). Assuming a different value of $40 \mathrm{~J} / \mathrm{K} / \mathrm{mol}$ (Kaiura and Toguri, 1979) does not significanlty change the resulting densities, slightly worsening the agreement with respect to experimental results, and making the isentropes moderately steeper.

The slopes of the adiabats obtained at selected pressures as a function of sulfur content are illustrated in Fig. 7 and compared with the slope of the liquidi (see section 2.5). It should be noted that the $\mathrm{S}$ concentrations considered here are always below the eutectic, where denser almost pure solid $\mathrm{Fe}$ is the phase crystallizing from the Fe-S liquid.

Observation of our different models highlights the dispersion depending on the chosen equation of state for liquid Fe. Nonetheless, on a qualitative ground, we note that the compositional domain for which the slope of the liquidus is larger than the adiabatic gradient is limited to a narrow portion on the Fe-rich side for all the pressure considered here (0-10 $\mathrm{GPa})$.

On one hand, due to decreasing thermal expansion and increasing density, the slope of the adiabat decreases with increasing pressure. At the conditions of Moon's (5.2 GPa) and Ganymede's (10 GPa) center, the adiabat only moderately depends on $\mathrm{S}$ content, as a consequence of the density reduction that overcomes the effect on $\mathrm{C}_{\mathrm{P}}$ (Fig. S2). On the other hand, the slope of the liquidus shows a significant decrease with increasing $\mathrm{S}$ content. The net effect is that, for Fe-S cores of small to middle size bodies (0 to $10 \mathrm{GPa}$ ) top-down solidification is the most likely scenario for wide range of S contents. Only for S-poor cases bottom-up inner grow is possible, like in the case of the Earth.

However, uncertainties on the relevant thermodynamic quantities resulting from the liquid equation of state of $\mathrm{Fe}$ and thermoelastic properties of 1-Fe-S alloys do not allow derivation of quantitative conclusions on the crystallization regime of planetary cores as a function of composition. For instance, assuming Model W, crystallization will always occurs top-down because the adiabatic gradient is always steeper than the liquidus over the pressure range considered here (Fig. 7c). Conversely, assuming the Model K or Model D, adiabatic gradients and the slope of the liquidus cross each other at $\mathrm{S}$ concentrations that increase with increasing pressure (Fig. 7a-b).

Paleomagnetic studies of chondritic and small-body achondritic meteorites have revealed a large diversity of magnetic field records (e.g. Weiss et al., 2020). Convection in the cores of differentiated, or at least partially differentiated asteroids, planetesimals, or meteoritic parent bodies in general, may have generated dynamo magnetic fields responsible for the magnetization of the overlying silicate rocks (Gattacceca et al., 2016; Weiss et al., 2008). 
While heating from short-living radioactive isotopes is generally considered to be responsible for the early dynamo, core solidification is expected to produce compositionally-driven dynamo activity, at a later stage with the timing dependent on the S concentration of the core and the radius of the body (Neufeld et al., 2019). At low pressures within an asteroid, isentropes are steeper than liquidus, irrespective of the $\mathrm{S}$ content for both models (b) and (c), while the adiabatic gradient is below the slope of the liquidus for alloys up to 4 at.\% $\mathrm{S}$ according to model (a) (Fig. 7). Top-down crystallization thus remains the most likely scenario, but bottom-up cannot be firmly excluded for very low S content. Generation of a magnetic field during top-down core crystallization could therefore be relatively common in differentiated planetesimals in the early age of the solar system.

Lunar core formation models based on metal/silicate partitioning of siderophile elements support a Moon core containing up to 10 at.\% S (Rai and Van Westrenen, 2014; Stenstra et al., 2017). Assuming a fully molten core in the binary Fe-S system, geodetic constraints argue for a larger amount of S, between 16 and 40 at.\%, depending on the core radius (Morard et al., 2018). The presence of a solid inner core, made of pure Fe, brings estimates down below 10 at.\% (Antonangeli et al., 2015). At about $5 \mathrm{GPa}$, the pressure at the center of the Moon, the adiabatic gradient and slope of the liquidus might cross at about 3 or about 9 at.\% $\mathrm{S}$, depending on the EOS of 1-Fe (Fig. 7). Accordingly, if the Moon does not have a solid inner core today, it will have most likely crystallized top down. On the contrary, if the existence of a solid inner core, as suggested by some seismological studies (Weber et al., 2011), is confirmed, its crystallization regime remains uncertain. That an initial bottom-up scenario, may have evolved into a top-down regime due to the progressive enrichment in $\mathrm{S}$ of the liquid portion of the core upon crystallization of pure $\mathrm{Fe}$, as hypothesized to explain the early, now extinct Moon magnetic field (e.g. Laneuville et al., 2014), remains an appealing possibility.

Compositional convection is considered a fundamental element to explain Ganymede's present-day dynamo (e.g. Rückriemen et al., 2018). In turn, compositional convection is strongly linked to core differentiation and solidification. Recently, significant efforts have been dedicated to model dynamics and magnetic field generation under the notion that crystallization occurs at the top of Ganymede's core (Breuer et al., 2015; Rückriemen et al., 2018 , 2015). Our results suggest this is not necessarily the case, and that crystallization might proceed bottom-up for $\mathrm{S}$ content below about 10 at $\%$. Indeed, the solution space for bottom-up crystallization might increase up to 7-11 at.\% $\mathrm{S}$, again depending on assumed liquid Fe equation of state, at $10 \mathrm{GPa}$, central pressure of Ganymede's core (Fig. 7). As both bottom-up and top-down crystallization can power a core dynamo and generate a magnetic field, although via different mechanisms, independent constraints on $\mathrm{S}$ abundance in Ganymede's core are needed to assess its thermo-chemical history.

\section{Conclusions}

We performed a structural investigation of liquid $\mathrm{Fe}-\mathrm{S}$ alloys at high pressure over a large temperature range and compositional domain. Derived densities have been used to refine thermodynamic models of the thermo-elastic properties of the liquid Fe-FeS system 
and, in particular, to put constraints on modeled thermal expansion at conditions directly relevant for the core of small planetary bodies.

Comparison of the adiabatic gradient with the slope of the liquidus, is used to discuss the crystallization regime of the core of planetary bodies in the range 0-10 GPa as a function of sulfur concentration, with specific emphasis to the case of asteroids and small planetesimals, the Moon, and Ganymede. Our results show that the compositional domain for which the slope of the liquidus is larger than the adiabatic gradient is limited to a narrow portion on the Fe-rich side for all the pressures considered here, implying that top-down crystallization is likely a widespread phenomenon. However, bottom-up crystallization is still possible for S-poor cases, and the compositional domain for which an inner core would grow bottom-up increases with increasing pressure. On the basis of our experimental results and thermodynamic modeling, a bottom-up scenario cannot be excluded to occur at the pressures of the core of the Moon and, all the more so, of Ganymede. Improved constraints on the liquid $\mathrm{Fe}$ EoS are needed to better discriminate possible scenarios.

\section{Acknowledgments}

The authors wish to thank Nicolas Dumesnil, Charlotte Georget and Philippe Rosier for their help with machining of the cell assembly parts. We also thank Tomoo Katsura for the access to the MDX machining equipment. We acknowledge Clemens Prescher, Silvia Boccato and Bin Zhao for their assistance in some of the experiments. We thank Imène Estève for her help with sample analysis by SEM, and Michel Fialin and Nicolas Rividi for their help during microprobe analysis. Femtosecond laser micromachining at the Institut de Minéralogie de Physique des Matériaux et de Cosmochimie (IMPMC), Paris, has been developed and realized by the "Cellule Project" with the financial support of ANR 2010-JCJC-604-01. The Scanning Electron Microscope (SEM) facility at IMPMC is supported by Région Ile de France grant SESAME 2006 NoI-07-593/R, INSU-CNRS, Institute de Physique (INP)-CNRS, University Pierre et Marie Curie-Paris 6, and by the French National Research Agency (ANR) grant ANR-07-BLAN-0124-01. This work was supported by the European Research Council (ERC) under the European Union's Horizon 2020 research and innovation Programme (grant number 724690). The work of AR was financially supported by the Belgian PRODEX program managed by the European Space Agency in collaboration with the Belgian Federal Science Policy Office. The authors acknowledge synchrotron SOLEIL for the provision of beamtime under proposals 20170506 , 20171307, 20181797 and 20190551.

\section{Reference}

Acuña, M.H., Connerney, J.E.P., Lin, R.P., Mitchell, D., Carlson, C.W., McFadden, J., Anderson, K.A., Rème, H., Mazelle, C., Vignes, D., 1999. Global distribution of crustal magnetization discovered by the Mars Global Surveyor MAG/ER experiment. Science (80-. ). 284, 790-793. 
Acuña, M.H., Connerney, J.E.P., Wasilewski, P., Lin, R.P., Mitchell, D., Anderson, K.A., Carlson, C.W., McFadden, J., Rème, H., Mazelle, C., Vignes, D., Bauer, S.J., Cloutier, P., Ness, N.F., 2001. Magnetic field of Mars: Summary of results from the aerobraking and mapping orbits. J. Geophys. Res. E Planets 106, 23403-23417. https://doi.org/10.1029/2000JE001404

Antonangeli, D., Morard, G., Schmerr, N.C., Komabayashi, T., Krisch, M., Fiquet, G., Fei, Y., Mao, H.K., 2015. Toward a mineral physics reference model for the Moon's core. Proc. Natl. Acad. Sci. U. S. A. 112, 3916-3919. https://doi.org/10.1073/pnas.1417490112 Assael, M.J., Kakosimos, K., Banish, R.M., Brillo, J., Egry, I., Brooks, R., Quested, P.N., Mills, K.C., Nagashima, A., Sato, Y., Wakeham, W.A., 2006. Reference data for the density and viscosity of liquid aluminum and liquid iron. J. Phys. Chem. Ref. Data 35, 285-300. https://doi.org/10.1063/1.2149380

Balog, P.S., Secco, R.A., Rubie, D.C., Frost, D.J., 2003. Equation of state of liquid Fe-10 wt \% S: Implications for the metallic cores of planetary bodies. J. Geophys. Res. Solid Earth 108. https://doi.org/10.1029/2001jb001646

Baonza, V.G., Caceres, M., Núñez, J., 1995. Universal compressibility behavior of dense phases. Phys. Rev. B 51, 28-37. https://doi.org/10.1103/PhysRevB.51.28

Brett, R., Bell, P.M., 1969. Melting relations in the Fe-rich portion of the system FeFeS at 30 $\mathrm{kb}$ pressure. Earth Planet. Sci. Lett. 6, 479-482. https://doi.org/10.1016/0012-821x(69)90119-8

Breuer, D., Hauck, S.A., Buske, M., Pauer, M., Spohn, T., 2007. Interior evolution of mercury. Space Sci. Rev. 132, 229-260. https://doi.org/10.1007/s11214-007-9228-9

Breuer, D., Rueckriemen, T., Spohn, T., 2015. Iron snow, crystal floats, and inner-core growth: modes of core solidification and implications for dynamos in terrestrial planets and moons. Prog. Earth Planet. Sci. 2. https://doi.org/10.1186/s40645-015-0069-y

Buono, A.S., Walker, D., 2011. The Fe-rich liquidus in the Fe-FeS system from 1 bar to 10GPa. Geochim. Cosmochim. Acta 75, 2072-2087. https://doi.org/10.1016/j.gca.2011.01.030

Chase, M.W., 1998. NIST-JANEF Thermochemical Tables, Fourth Edition. J. Phys. Chem.

Chen, B., Li, J., Hauck, S.A., 2008. Non-ideal liquidus curve in the Fe-S system and Mercury ' s snowing core 35, 10-14. https://doi.org/10.1029/2008GL033311

Chen, J., Yu, T., Huang, S., Girard, J., Liu, X., 2014. Compressibility of liquid FeS measured using X-ray radiograph imaging. Phys. Earth Planet. Inter. 228, 294-299. https://doi.org/10.1016/j.pepi.2013.12.012

Connerney, J.E.P., Acuña, M.H., Wasilewski, P.J., Kletetschka, G., Ness, N.F., Rème, H., Lin, R.P., Mitchell, D.L., 2001. The global magnetic field of Mars and implications for crustal evolution. Geophys. Res. Lett. 28, 4015-4018. https://doi.org/10.1029/2001GL013619

Davies, C.J., Pozzo, M., Alfé, D., 2019. Assessing the inner core nucleation paradox with atomic-scale simulations. Earth Planet. Sci. Lett. 507, 1-9. https://doi.org/10.1016/j.eps1.2018.11.019

Dorogokupets, P.I., Dymshits, A.M., Litasov, K.D., Sokolova, T.S., 2017. Thermodynamics and Equations of State of Iron to $350 \mathrm{GPa}$ and $6000 \mathrm{~K}$. Sci. Rep. 7, 1-11. https://doi.org/10.1038/srep41863 
Dumberry, M., Rivoldini, A., 2015. Mercury's inner core size and core-crystallization regime. Icarus 248, 254-268. https://doi.org/10.1016/j.icarus.2014.10.038

Eggert, J.H., Weck, G., Loubeyre, P., Mezouar, M., 2002. Quantitative structure factor and density measurements of high-pressure fluids in diamond anvil cells by x-ray diffraction: Argon and water. Phys. Rev. B - Condens. Matter Mater. Phys. 65, 1-12. https://doi.org/10.1103/PhysRevB.65.174105

Gattacceca, J., Weiss, B.P., Gounelle, M., 2016. New constraints on the magnetic history of the CV parent body and the solar nebula from the Kaba meteorite. Earth Planet. Sci. Lett. 455, 166-175. https://doi.org/10.1016/j.eps1.2016.09.008

Hauck, S.A., Aurnou, J.M., Dombard, A.J., 2006. Sulfur's impact on core evolution and magnetic field generation on Ganymede. J. Geophys. Res. E Planets 111, 1-14. https://doi.org/10.1029/2005JE002557

Hixson, R.S., Winkler, M.A., Hodgdon, M.L., 1990. Sound speed and thermophysical properties of liquid iron and nickel. Phys. Rev. B 42, 6485-6491. https://doi.org/10.1103/PhysRevB.42.6485

Huguet, L., Van Orman, J.A., Hauck, S.A., Willard, M.A., 2018. Earth's inner core nulceation paradox. Earth Planet. Sci. Lett. 487, 9-20. https://doi.org/10.1016/j.epsl.2018.01.018

Kaiura, G.H., Toguri, J.M., 1979. Densities of the molten FeS, FeS-Cu2S AND Fe-S-O systems-utilizing a bottom-balance archimedean technique. Can. Metall. Q. 18, 155-164. https://doi.org/10.1179/cmq.1979.18.2.155

Kivelson, M.G., Khurana, K.K., Coroniti, F. V, Joy, S., Russell, C.T., Walker, R.J., Warnecke, J., Bennett, L., Polanskey, C., 1997. The magnetic field and magnetosphere of Ganymede. Geophys. Res. Lett. 24, 2155-2158.

Komabayashi, T., 2014. Thermodynamics of melting relations in the system Fe-FeO at high pressure: Implications for oxygen in the Earth's core. J. Geophys. Res. Solid Earth 119, 4164-4177. https://doi.org/10.1002/2014JB010980

Laneuville, M., Wieczorek, M.A., Breuer, D., Aubert, J., Morard, G., Rückriemen, T., 2014. A long-lived lunar dynamo powered by core crystallization. Earth Planet. Sci. Lett. 401, 251-260. https://doi.org/10.1016/j.eps1.2014.05.057

Morard, G., Bouchet, J., Rivoldini, A., Antonangeli, D., Roberge, M., Boulard, E., Denoeud, A., Mezouar, M., 2018. Liquid properties in the Fe-FeS system under moderate pressure: Tool box to model small planetary cores. Am. Mineral. 103, 1770-1779. https://doi.org/10.2138/am-2018-6405

Morard, G., Garbarino, G., Antonangeli, D., Andrault, D., Guignot, N., Siebert, J., Roberge, M., Boulard, E., Lincot, A., Denoeud, A., Petitgirard, S., 2014. Density measurements and structural properties of liquid and amorphous metals under high pressure. High Press. Res. 34, 9-21. https://doi.org/10.1080/08957959.2013.860137

Morard, G., Nakajima, Y., Andrault, D., Antonangeli, D., Auzende, A.L., Boulard, E., Cervera, S., Clark, A.N., Lord, O.T., Siebert, J., Svitlyk, V., Garbarino, G., Mezouar, M., 2017. Structure and Density of Fe-C Liquid Alloys Under High Pressure. J. Geophys. Res. Solid Earth 122, 7813-7823. https://doi.org/10.1002/2017JB014779

Morard, G., Siebert, J., Andrault, D., Guignot, N., Garbarino, G., Guyot, F., Antonangeli, D., 2013. The Earth's core composition from high pressure density measurements of liquid iron alloys. Earth Planet. Sci. Lett. 373, 169-178. 
Nagamori, M., 1969. Density of molten Ag-S, Cu-S, Fe-S, and Ni-S systems. Trans. Metall. Soc. AIME 245, 1897-1902.

Nasch, P.M., Manghnani, M.H., Secco, R.A., 1994. Sound velocity measurements in liquid iron by ultrasonic interferometry. J. Geophys. Res. 99, 4285-4291. https://doi.org/10.1029/93JB03111

653

654

Nasch, P.M., Steinemann, S.G., 1995. Density and thermal expansion of molten manganese, iron, nickel, copper, aluminum and tin by means of the gamma-ray attenuation technique. Phys. Chem. Liq. 29, 43-58.

Ness, N.F., 1979. The magnetic field of Mercury. Phys. Earth Planet. Inter. 20, 209-217. https://doi.org/10.1016/0031-9201(79)90044-X

Neufeld, J.A., Bryson, J.F.J., Nimmo, F., 2019. The Top-Down Solidification of Iron Asteroids Driving Dynamo Evolution. J. Geophys. Res. Planets 124, 1331-1356. https://doi.org/10.1029/2018JE005900

Nishida, K., Ohtani, E., Urakawa, S., Suzuki, A., Sakamaki, T., Terasaki, H., Katayama, Y., 2011. Density measurement of liquid FeS at high pressures using synchrotron X-ray absorption. Am. Mineral. 96, 864-868. https://doi.org/10.2138/am.2011.3616

Nishida, K., Suzuki, A., Terasaki, H., Shibazaki, Y., Higo, Y., Kuwabara, S., Shimoyama, Y., Sakurai, M., Ushioda, M., Takahashi, E., Kikegawa, T., Wakabayashi, D., Funamori, N., 2016. Towards a consensus on the pressure and composition dependence of sound velocity in the liquid $\mathrm{Fe}-\mathrm{S}$ system. Phys. Earth Planet. Inter. 257, 230-239. https://doi.org/10.1016/j.pepi.2016.06.009

Nishida, K., Terasaki, H., Ohtani, E., Suzuki, A., 2008. The effect of sulfur content on density of the liquid Fe-S at high pressure. Phys. Chem. Miner. 35, 417-423. https://doi.org/10.1007/s00269-008-0236-4

Rai, N., Van Westrenen, W., 2014. Lunar core formation: New constraints from metal-silicate partitioning of siderophile elements. Earth Planet. Sci. Lett. 388, 343-352. https://doi.org/10.1016/j.eps1.2013.12.001

Rivoldini, A., Van Hoolst, T., Verhoeven, O., Mocquet, A., Dehant, V., 2011. Geodesy constraints on the interior structure and composition of Mars. Icarus 213, 451-472. https://doi.org/10.1016/j.icarus.2011.03.024

Rückriemen, T., Breuer, D., Spohn, T., 2018. Top-down freezing in a Fe-FeS core and Ganymede's present-day magnetic field. Icarus 307, 172-196. https://doi.org/10.1016/j.icarus.2018.02.021

Rückriemen, T., Breuer, D., Spohn, T., 2015. The Fe snow regime in Ganymede's core: A deep-seated dynamo below a stable snow zone. J. Geophys. Res. E Planets 120, 10951118. https://doi.org/10.1002/2014JE004781

Sanloup, C., Drewitt, J.W.E., Konôpková, Z., Dalladay-Simpson, P., Morton, D.M., Rai, N., Van Westrenen, W., Morgenroth, W., 2013. Structural change in molten basalt at deep mantle conditions. Nature 503, 104-107. https://doi.org/10.1038/nature12668

Sanloup, C., Guyot, F., Gillet, P., Fiquet, G., Mezouar, M., Martinez, I., 2000. Density measurements of liquid Fe-S alloys at high-pressure. Geophys. Res. Lett. 27, 811-814. https://doi.org/10.1029/1999GL008431

Scott, H.P., Williams, Q., Ryerson, F.J., 2002. Experimental constraints on the chemical 
evolution of large icy satellites. Earth Planet. Sci. Lett. 203, 399-412. https://doi.org/10.1016/S0012-821X(02)00850-6

Shibazaki, Y., Kono, Y., 2018. Effect of Silicon, Carbon, and Sulfur on Structure of Liquid Iron and Implications for Structure-Property Relations in Liquid Iron-Light Element Alloys. J. Geophys. Res. Solid Earth 123, 4697-4706. https://doi.org/10.1029/2018JB015456

Silber, R.E., Secco, R.A., Yong, W., Littleton, J.A.H., 2018. Electrical resistivity of liquid Fe to $12 \mathrm{GPa}$ : Implications for heat flow in cores of terrestrial bodies. Sci. Rep. 8, 10758. https://doi.org/10.1038/s41598-018-28921-w

Stacey, F.D., 2005. High pressure equations of state and planetary interiors. Reports Prog. Phys. 68, 341-383. https://doi.org/10.1088/0034-4885/68/2/R03

Steenstra, E.S., Lin, Y., Dankers, D., Rai, N., Berndt, J., Matveev, S., van Westrenen, W., 2017. The lunar core can be a major reservoir for volatile elements S, Se, Te and Sb. Sci. Rep. 7, 14552. https:// doi.org/10.1038/s41598-017-15203-0

Stevenson, D.J., 2003. Planetary magnetic fields. Earth Planet. Sci. Lett. 208, 1-11. https://doi.org/10.1016/S0012-821X(02)01126-3

Tange, Y., Nishihara, Y., Tsuchiya, T., 2009. Unified analyses for P - V - T equation of state of MgO: A solution for pressure-scale problems in high $\mathrm{P}-\mathrm{T}$ experiments . J. Geophys. Res. 114, 1-16. https://doi.org/10.1029/2008jb005813

Terasaki, H., Rivoldini, A., Shimoyama, Y., Nishida, K., Urakawa, S., Maki, M., Kurokawa, F., Takubo, Y., Shibazaki, Y., Sakamaki, T., Machida, A., Higo, Y., Uesugi, K., Takeuchi, A., Watanuki, T., Kondo, T., 2019. Pressure and Composition Effects on Sound Velocity and Density of Core-Forming Liquids: Implication to Core Compositions of Terrestrial Planets. J. Geophys. Res. Planets 124, 2272-2293. https://doi.org/10.1029/2019JE005936

Wagle, F., Steinle-Neumann, G., 2019. Liquid Iron Equation of State to the Terapascal Regime From Ab Initio Simulations. J. Geophys. Res. Solid Earth 124, 3350-3364. https://doi.org/10.1029/2018JB016994

Waldner, P., Pelton, A.D., 2005. Thermodynamic modeling of the Fe-S system. J. Phase Equilibria Diffus. 26, 23-38. https://doi.org/10.1361/15477030522455

Wang, Y., Uchida, T., Von Dreele, R., Rivers, M.L., Nishiyama, N., Funakoshi, K.I., Nozawa, A., Kaneko, H., 2004. A new technique for angle-dispersive powder diffraction using an energy-dispersive setup and synchrotron radiation. J. Appl. Crystallogr. 37, 947-956. https://doi.org/10.1107/S0021889804022502

Weber, R.C., Lin, P.Y., Garnero, E.J., Williams, Q., Lognonné, P., 2011. Seismic detection of the lunar core. Science (80-. ). 331, 309-312. https://doi.org/10.1126/science.1199375

Weiss, B.P., Berdahl, J.S., Elkins-tanton, L., Stanley, S., Lima, E.A., Carporzen, L., 2020. a 322, 713-716.

Weiss, B.P., Berdahl, J.S., Elkins-Tanton, L., Stanley, S., Lima, E.A., Carporzen, L., 2008. Magnetism on the angrite parent body and the early differentiation of planetesimals. Science (80-. ). 322, 713-716.

Weiss, B.P., Tikoo, S.M., 2014. The lunar dynamo. Science (80-. ). 346. https://doi.org/10.1126/science.1246753

Williams, Q., 2009. Bottom-up versus top-down solidification of the cores of small solar 
system bodies: Constraints on paradoxical cores. Earth Planet. Sci. Lett. 284, 564-569. https://doi.org/10.1016/j.epsl.2009.05.019

Xie, L., Yoneda, A., Xu, F., Higo, Y., Wang, C., Tange, Y., King, A., Antonangeli, D., Morard, G., Guignot, N., 2020. Boron-MgO composite as an X-ray transparent pressure medium in the multi-anvil apparatus. Rev. Sci. Instrum. 91, 043903. https://doi.org/10.1063/1.5137740

Yamada, A., Inoue, T., Urakawa, S., Funakoshi, K.I., Funamori, N., Kikegawa, T., Ohfuji, H., Irifune, T., 2007. In situ X-ray experiment on the structure of hydrous Mg-silicate melt under high pressure and high temperature. Geophys. Res. Lett. 34, 1-5. https://doi.org/10.1029/2006GL028823

Yamada, A., Wang, Y., Inoue, T., Yang, W., Park, C., Yu, T., Shen, G., 2011. High-pressure $\mathrm{X}$-ray diffraction studies on the structure of liquid silicate using a Paris-Edinburgh type large volume press. Rev. Sci. Instrum. 82, 1-7. https://doi.org/10.1063/1.3514087 
750 Table 1 Chemical composition of quenched samples, pressure-temperature conditions, and 751 measured densities and position of the first sharp peak $r 1$. The density scaled to a constant 752 pressure of $7 \mathrm{GPa}$ is also shown.

\begin{tabular}{|c|c|c|c|c|c|c|}
\hline Run & $\begin{array}{l}\text { S content } \\
\text { (at.\%) }\end{array}$ & $\begin{array}{l}\text { Pressure } \\
(\mathrm{GPa})\end{array}$ & $\begin{array}{c}\text { Temperature } \\
\text { (K) }\end{array}$ & $\begin{array}{l}\text { Density } \\
(\mathrm{kg} / \mathrm{m} 3)\end{array}$ & $\begin{array}{l}\text { Density corrected } \\
\text { to } 7 \mathrm{GPa}(\mathrm{kg} / \mathrm{m} 3)\end{array}$ & $r 1(\AA)$ \\
\hline \multirow[t]{5}{*}{ MA84 } & $51.2 \pm 0.4$ & 6.5 & 1700 & 4486 & 4521 & 2.374 \\
\hline & & 6.8 & 1800 & 4427 & 4440 & 2.375 \\
\hline & & 6.8 & 1900 & 4332 & 4345 & 2.376 \\
\hline & & 6.5 & 2000 & 4286 & 4319 & 2.379 \\
\hline & & 5.7 & 2100 & 4222 & 4312 & 2.378 \\
\hline \multirow[t]{8}{*}{ MA40 } & $38.3 \pm 0.5$ & 6.5 & 1280 & 5619 & 5659 & 2.440 \\
\hline & & 6.4 & 1400 & 5526 & 5578 & 2.442 \\
\hline & & 6.4 & 1500 & 5511 & 5562 & 2.442 \\
\hline & & 6.7 & 1320 & 5619 & 5642 & 2.446 \\
\hline & & 6.6 & 1310 & 5619 & 5654 & 2.446 \\
\hline & & 6.9 & 1500 & 5573 & 5577 & 2.440 \\
\hline & & 6.0 & 1600 & 5464 & 5545 & 2.446 \\
\hline & & 6.1 & 1790 & 5348 & 5420 & 2.439 \\
\hline \multirow[t]{5}{*}{ MA44 } & $31.7 \pm 0.9$ & 7.1 & 1415 & 5944 & 5938 & 2.450 \\
\hline & & 6.9 & 1500 & 5880 & 5889 & 2.447 \\
\hline & & 6.8 & 1610 & 5800 & 5817 & 2.451 \\
\hline & & 7.0 & 1710 & 5720 & 5721 & 2.454 \\
\hline & & 6.9 & 1800 & 5656 & 5666 & 2.454 \\
\hline \multirow[t]{6}{*}{ MA47 } & $25.1 \pm 0.3$ & 7.5 & 1600 & 6211 & 6171 & 2.485 \\
\hline & & 7.5 & 1705 & 6160 & 6119 & 2.485 \\
\hline & & 7.8 & 1790 & 6137 & 6077 & 2.489 \\
\hline & & 7.9 & 1900 & 6084 & 6018 & 2.486 \\
\hline & & 8.4 & 2050 & 6059 & 5956 & 2.484 \\
\hline & & 8.3 & 2020 & 6043 & 5951 & 2.486 \\
\hline \multirow[t]{4}{*}{ MA82 } & $18.1 \pm 0.4$ & 5.6 & 1500 & 6308 & 6416 & 2.502 \\
\hline & & 5.3 & 1600 & 6291 & 6423 & 2.512 \\
\hline & & 5.4 & 1700 & 6188 & 6310 & 2.515 \\
\hline & & 5.2 & 1800 & 6171 & 6309 & 2.520 \\
\hline \multirow[t]{5}{*}{ MA66 } & $9.1 \pm 0.5$ & 6.8 & 1850 & 6746 & 6759 & 2.541 \\
\hline & & 7.1 & 1950 & 6711 & 6704 & 2.553 \\
\hline & & 7.4 & 2050 & 6647 & 6621 & 2.555 \\
\hline & & 7.7 & 2155 & 6569 & 6524 & 2.554 \\
\hline & & 8.1 & 2250 & 6520 & 6451 & 2.554 \\
\hline \multirow[t]{3}{*}{ MA58 } & $8.4^{*}$ & 5.5 & 1825 & 6717 & 6880 & 2.537 \\
\hline & & 5.4 & 1960 & 6599 & 6766 & 2.541 \\
\hline & & 4.7 & 2075 & 6487 & 6703 & 2.554 \\
\hline
\end{tabular}

$754 \S$ The uncertainty of \pm 3 atoms $/ \mathrm{nm}^{3}$ estimated for the used protocol in data analysis (Morard 
755 et al., 2013), reflects into an error of 220, 230, 240, 250, 260 and $270 \mathrm{~kg} / \mathrm{m}^{3}$ for $51.2,38.3$, $756 \quad 31.7,25.1,18.1$ and 9.1 at.\% $\mathrm{S}$ content, respectively

757 * Starting composition; analysis of the recovered sample was not possible due to the leak of 758 the sample at further high temperature.

759

760 
(a)

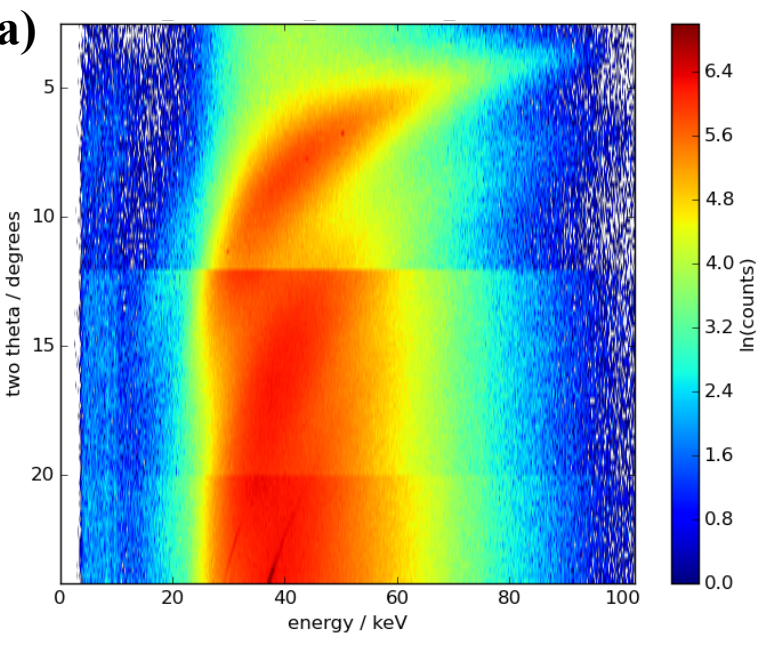

(b)

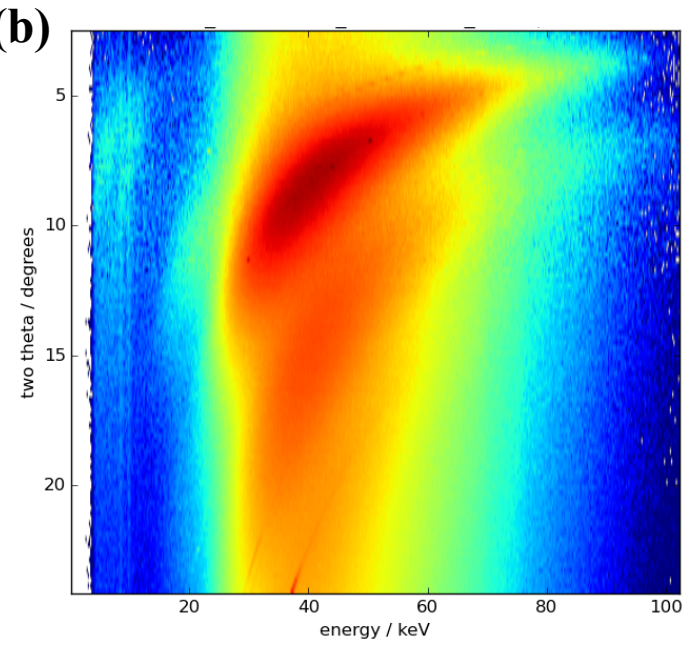

(c)

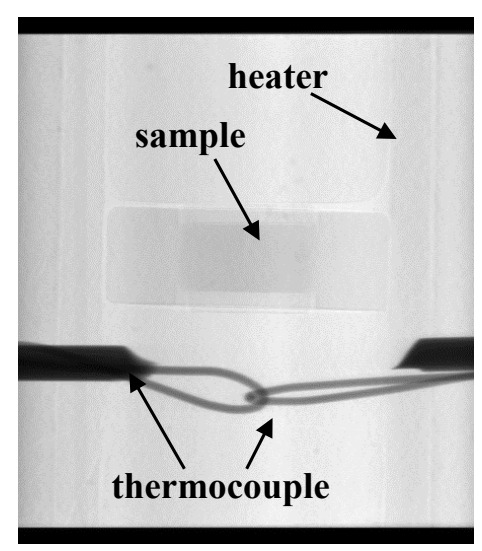

(d)

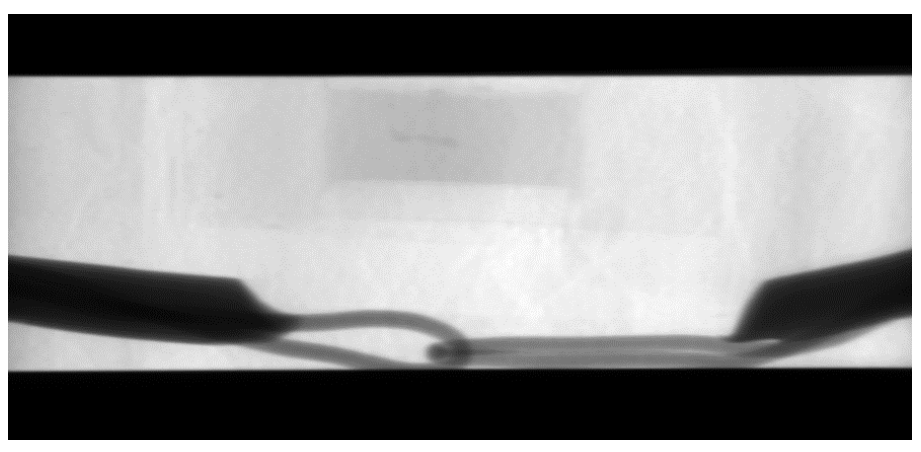

Fig. $1(a, b)$ Two-dimensional CAESAR plot of diffraction intensities collected on liquid FeS (run MA84). Raw 2D data (EDD spectra as a function of angle) (a) and data after normalization for acquisition time and binning (b). The discontinuities visible in (a) for $2 \theta=12^{\circ}$ and $20^{\circ}$ are due to the change of acquisition time. (c, d) Images of cell assemblies obtained by X-ray radiography before compression (a) and at $6.3 \mathrm{GPa}$ (c) after reaching to the target load. 


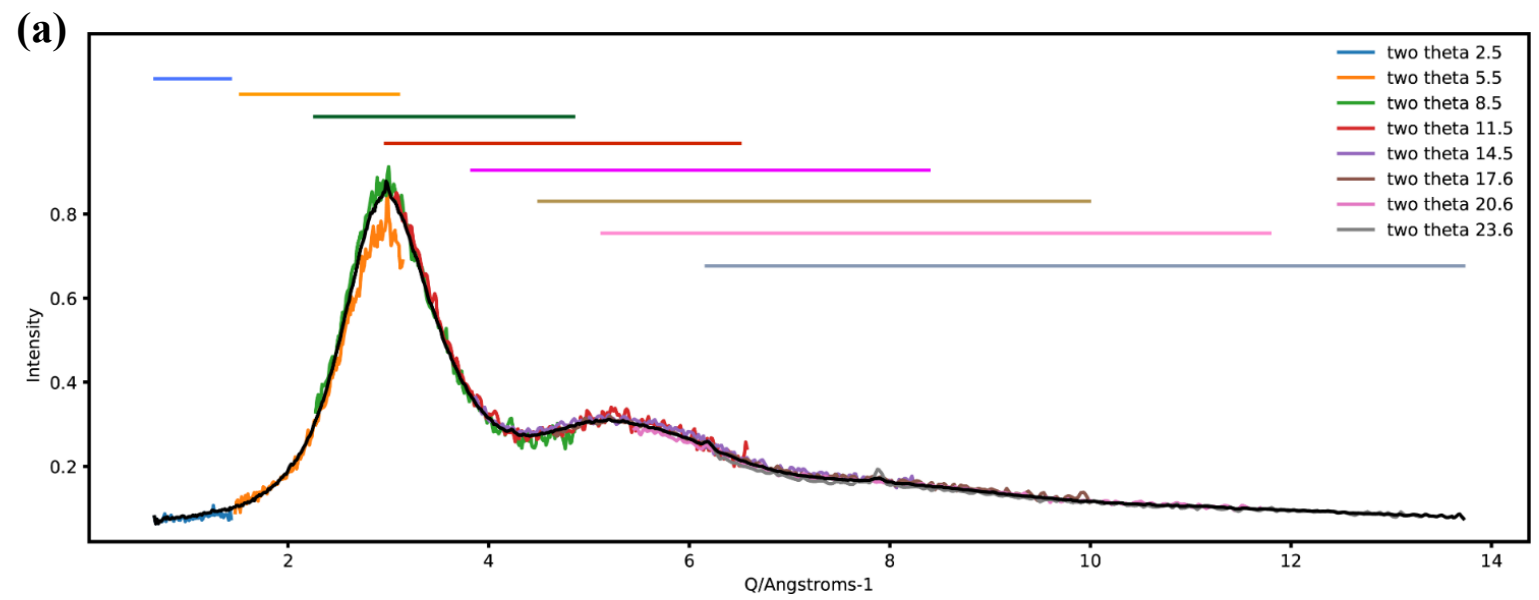

(b)

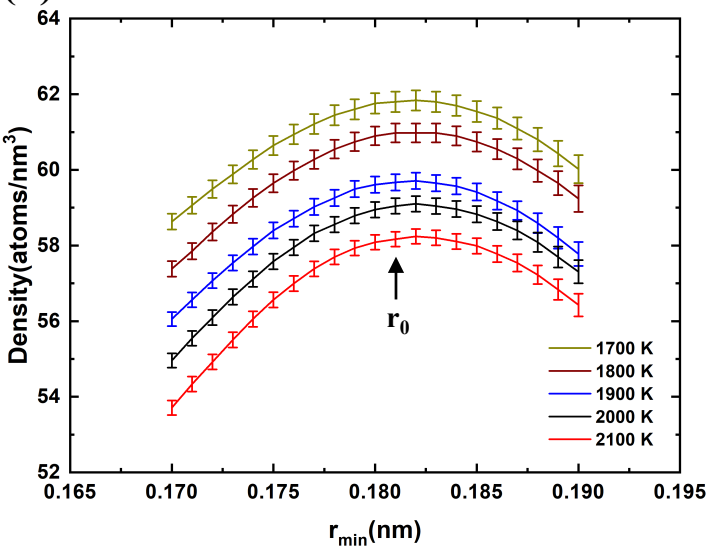

(c)

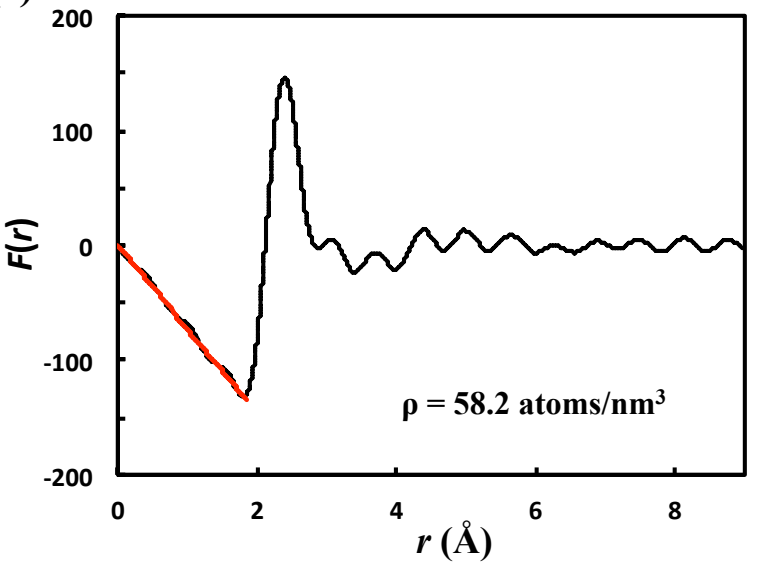

Fig. 2 Examples of raw CAESAR data treatment process. (a) Normalized scattering intensity plotted as a function of $\mathrm{Q}$. Color-coded horizontal bars and overlapping $\mathrm{I}(\mathrm{Q})$ patterns illustrate the $\mathrm{Q}$ range covered and $I(Q)$ derived from the EDX spectra at corresponding $2 \theta$. (b) Atomic densities calculated for different values of the minimal distance $r_{\text {min }}$. Error bars indicate the value of merit $\chi^{2}$ for each $\mathrm{r}_{\min }$ (see Morard et al. (2013) for more details). Arrow points out the local minimum of $\chi^{2}$, providing atomic density and $r_{0}$ for this data set. We stress that the temperature dependence of density is effectively independent of $r_{\min }$. (c) Comparison of the distribution function $F(r)$ with the function $-4 \pi \mathrm{r} \rho_{0}$ (dashed lines) calculated using density obtained by $\chi^{2}$ minimization (d) $(2100 \mathrm{~K})$. 

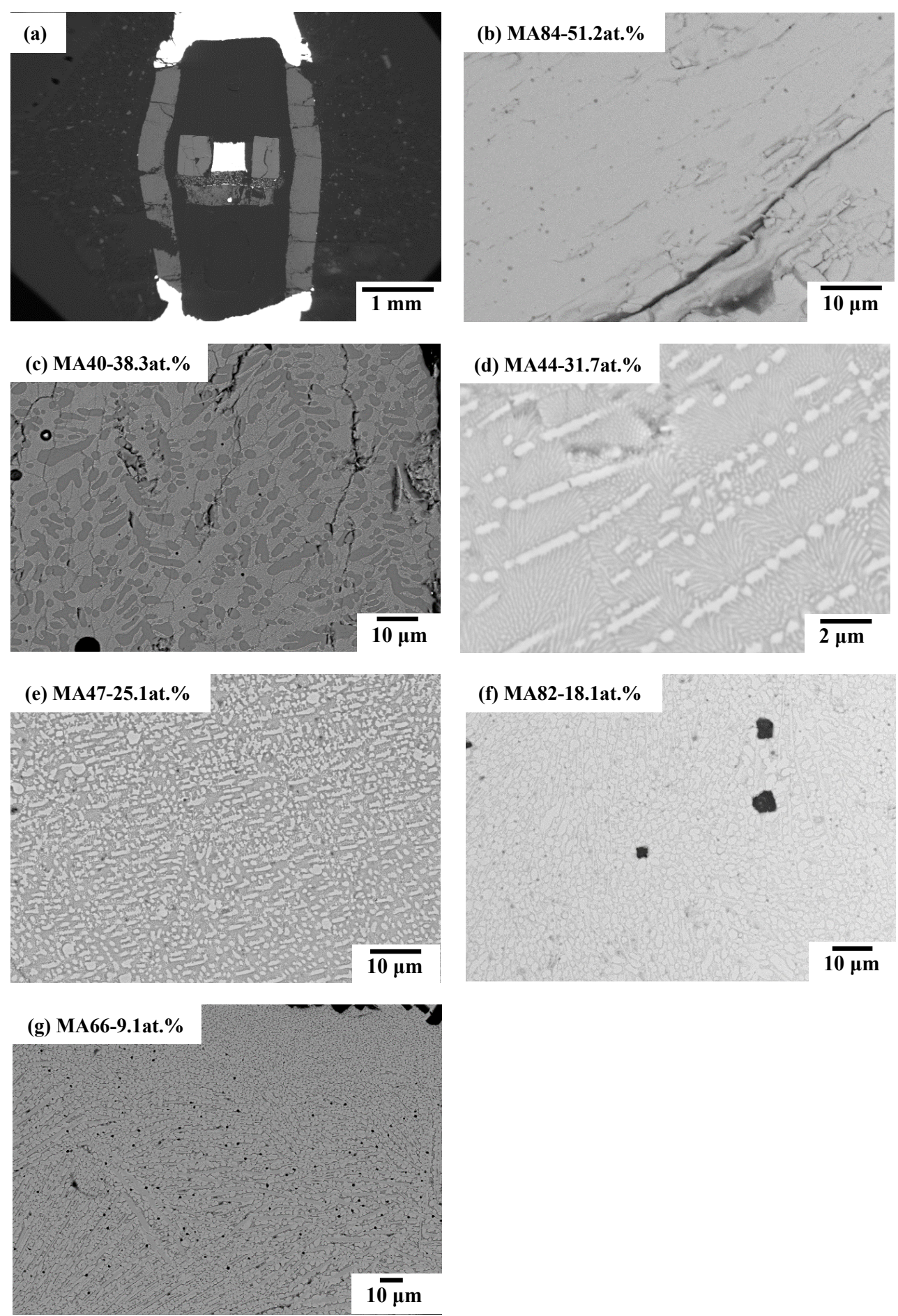

795 Fig. 3 Backscattered electron image of recovered samples. (a) An overall view of the recovered cell after run MA47. (b-g) Microstructure of the recovered samples of the indicated runs. In (c-g) brighter areas correspond to Fe-rich portions of the sample, while darker areas correspond to S-rich portions. 

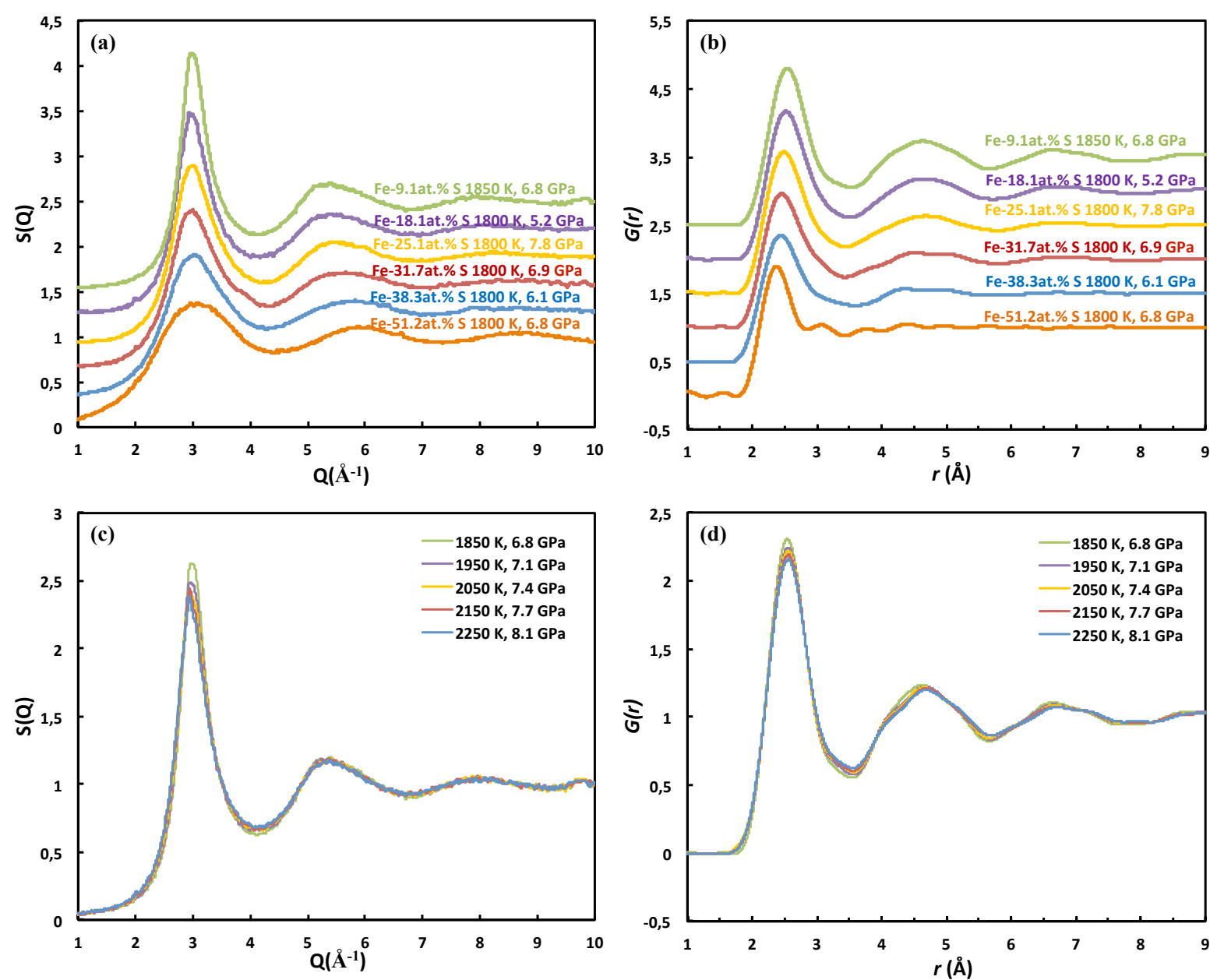

804 Fig. 4 Examples of structure factor, $S(Q)$, and pair distribution function, $g(r)$, of liquids Fe-S 805 alloys at high pressure and high temperature. (a) $S(Q)$ and (b) $g(r)$ as a function of S content.

806 For clarity, $S(Q)$ and $g(r)$ are shown with a vertical offset of 0.3 and 0.5 in (a) and (b), 807 respectively. Oscillations at $\sim 4.4$ and $5.0 \AA$ visible in (b) for $\mathrm{S}$ concentration larger than 808 31.7at.\% are not real features and arise from spurious signal due to the limited Q range in the corresponding structure factors. (c) $S(Q)$ and (d) $G(r)$ of Fe-9.1at.\% $\mathrm{S}$ as a function of temperature (MA66). 


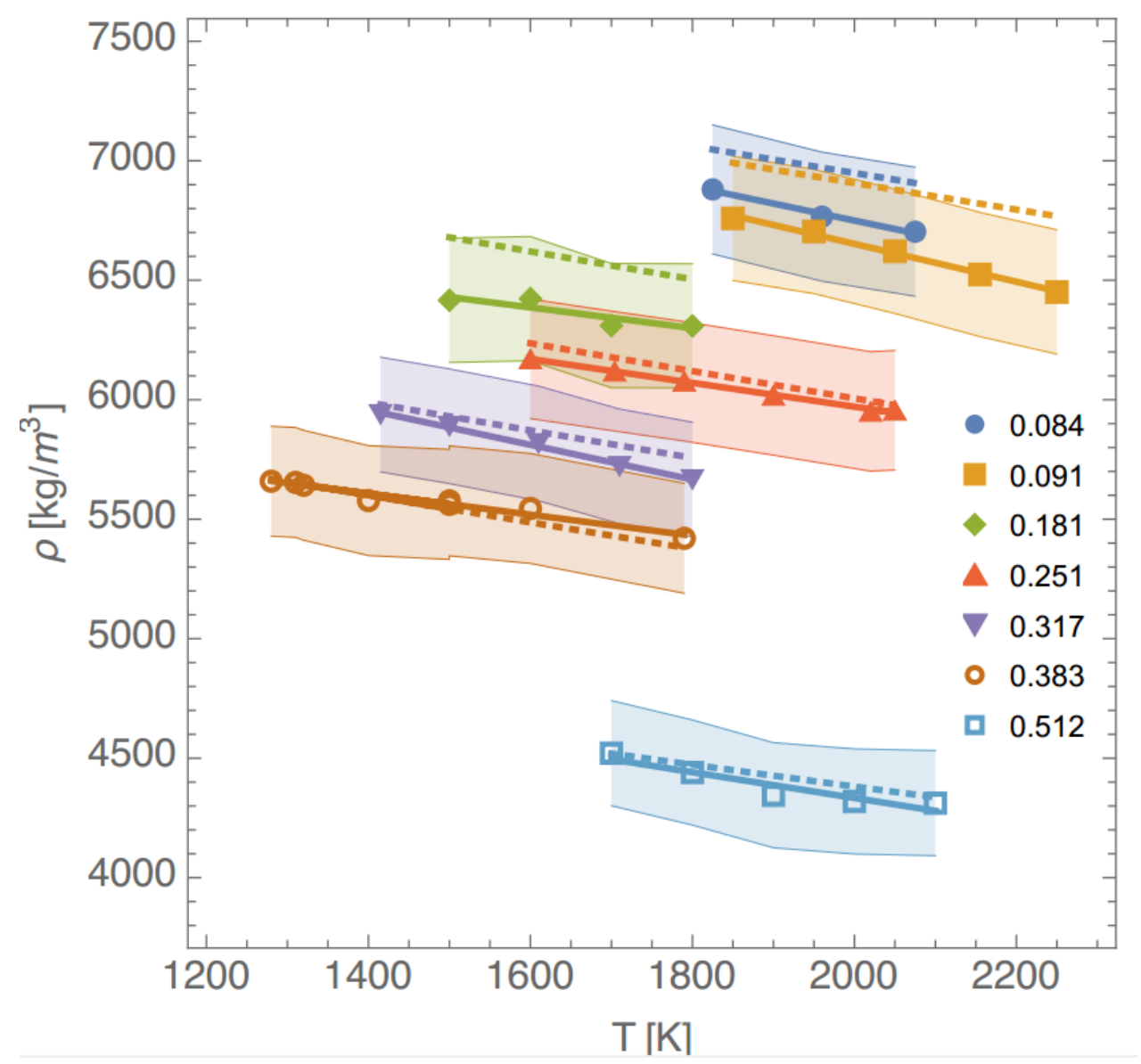

817 Fig. 5 Temperature dependence of the density of liquid Fe-S alloys at constant pressure (7 $818 \mathrm{GPa}$ ). Linear fit of our data (solid line) and temperature derivative according to the 819 thermodynamic Model W (dashed lines). Legend: atomic S concentration. Hatched areas 820 indicate uncertainties on absolute density values $\left( \pm 3\right.$ atoms $/ \mathrm{nm}^{3}$, see section 2.3 ). Reported 821 liquid compositions are those determined by chemical analysis of quenched and recovered 822 samples but for the experiment on $\mathrm{Fe}-\mathrm{S}_{0.084}$ for which we considered the composition of the 823 starting material. 


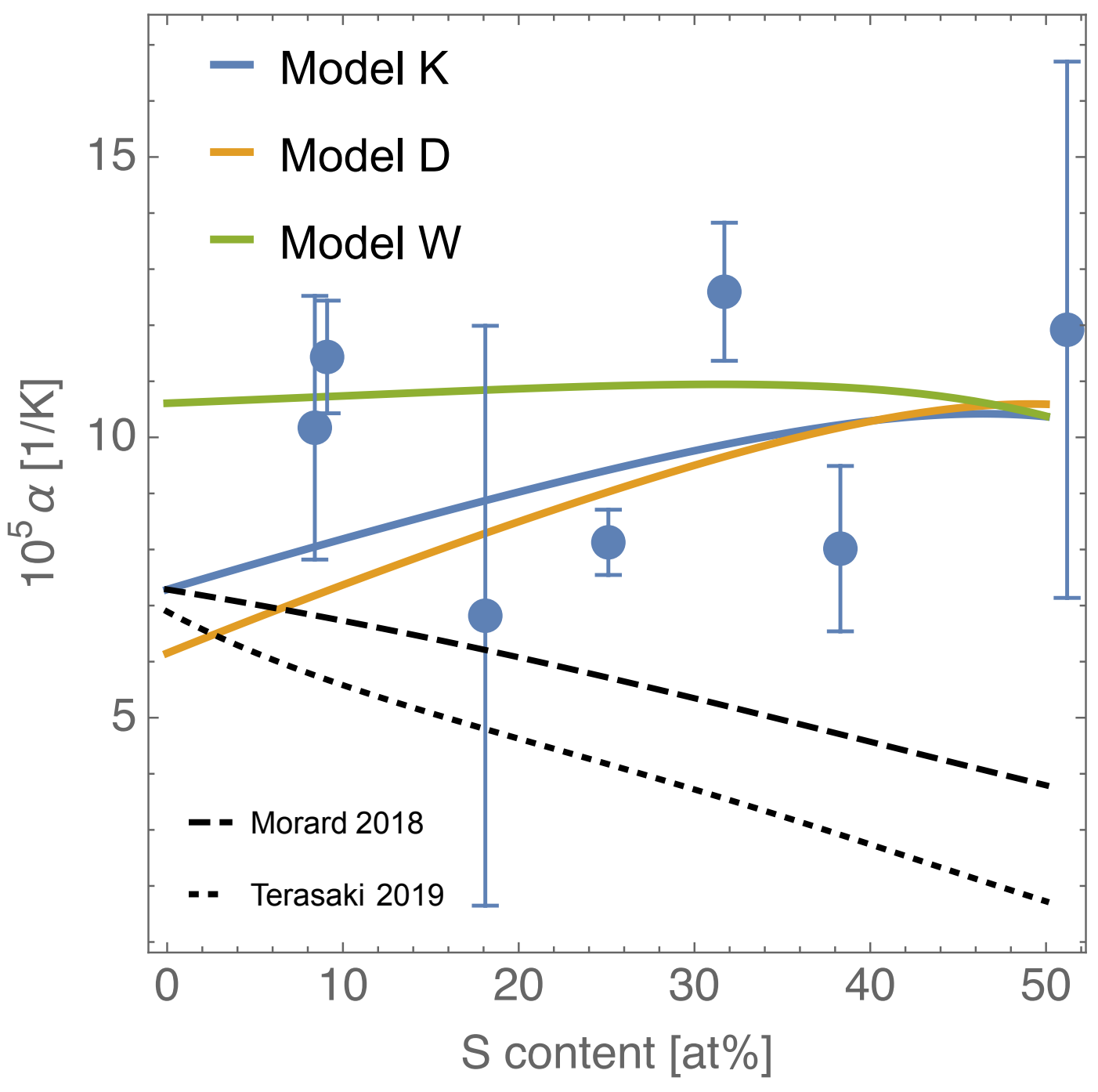

830 Fig. 6 Thermal expansivity as function of sulfur content at $7 \mathrm{GPa}$ and $2000 \mathrm{~K}$. Dots are 831 estimations from experiments while colored lines are outcomes of thermodynamic models Model K (blue), Model D (orange), and Model W) (green). Please refer to section 2.5 for details on the thermodynamic models and Table S1 and S2 for the used parameters. Black lines are results from literature thermodynamic models (dotted - Terasaki et al., 2019; dashed - Morard et al., 2018).

836

837

838 

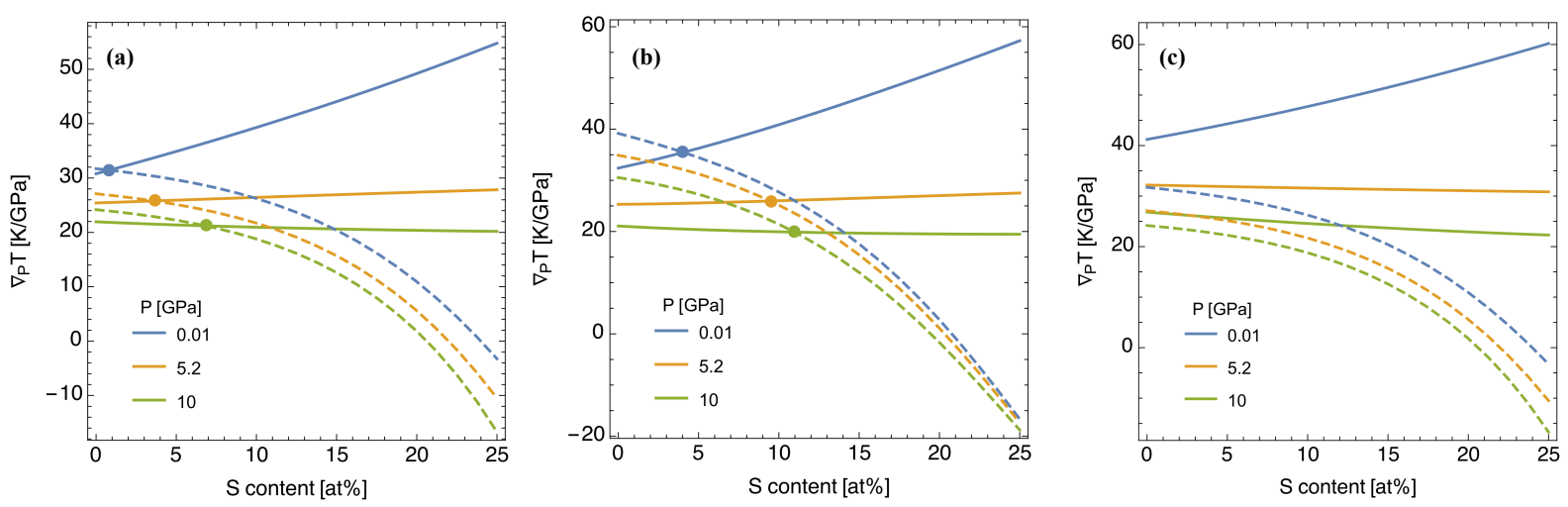

Fig. 7 Adiabatic gradient (solid lines) and slope of the liquidus (dashed lines) as a function of the $\mathrm{S}$ content at $0.01 \mathrm{GPa}, 5.2 \mathrm{GPa}$, and $10 \mathrm{GPa}$, corresponding to core pressure of planetesimals, Moon and Ganymede, respectively, for the Model K (a), Model D (b), and Model W (2019) (c). Note that for the Model W the EOS' of solid Fe from Komabayashi (2014) has been used to compute the slope of the liquidi. For other differences in the models, please refer to section 2.5 and to Table S1 and S2 for the used parameters. 


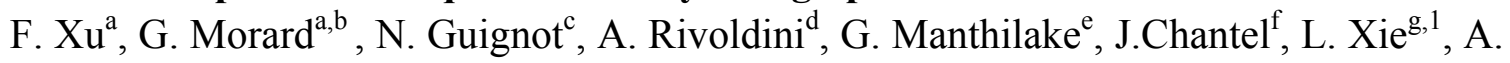
Yoneda $^{\text {h }}$, A. King ${ }^{\text {c }}$, E. Boulard ${ }^{\text {a }}$, S. Pandolfi ${ }^{\mathrm{a}, 2}$, F. J. Ryerson ${ }^{\mathrm{i}}$, D. Antonangeli ${ }^{\mathrm{a},{ }^{*}}$

Sorbonne Université, Muséum National d'Histoire Naturelle, UMR CNRS 7590, Institut de Minéralogie, de Physique des Matériaux et de Cosmochimie, IMPMC, 75005 Paris, France

$860{ }^{\mathrm{b}}$ Université Grenoble Alpes, Université Savoie Mont Blanc, CNRS, IRD, Université Gustave Eiffel, ISTerre, 38000 Grenoble, France

' Synchrotron SOLEIL, L’Orme de Merisiers, Saint Aubin-BP48, 91192 Gif-sur-Yvette, France

${ }^{\mathrm{d}}$ Royal Observatory of Belgium, Avenue Circulaire 3, B-1180 Brussels, Belgium

e Laboratoire Magmas et Volcans CNRS, IRD, OPGC, Université Clermont Auvergne, 63000 Clermont-Ferrand, France

${ }^{\mathrm{f}}$ Univ. Lille, CNRS, INRAE, Centrale Lille, UMR 8207 - UMET - Unité Matériaux et Transformations, F-59000 Lille, France

g Institute for Planetary Materials, Okayama University, Misasa, Tottori 682-0193, Japan

$\mathrm{h}$ Department of Earth and Space Science, Graduate School for Science, Osaka University, Toyonaka, Osaka 560-0043, Japan

${ }^{\text {i }}$ Lawrence Livermore National Laboratory, 7000 East Avenue, Livermore, California 94550-9698, U.S.A

${ }^{1}$ Currently at Bayerisches Geoinstitut, Universität Bayreuth, 95440 Bayreuth, Germany

${ }^{2}$ Currently at Fundamental Physics Directorate, SLAC National Accelerator Laboratory, Menlo Park, CA, United States

*Corresponding author.

881 
(a)

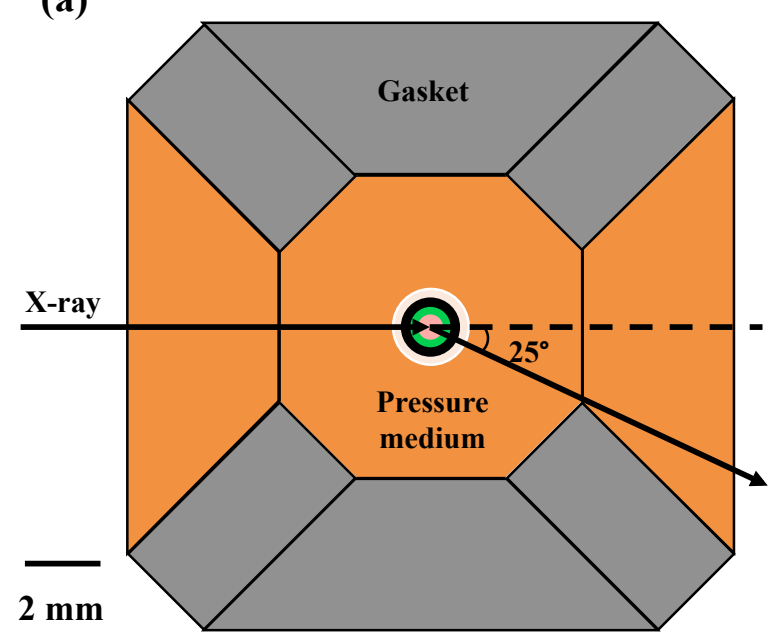

(b)

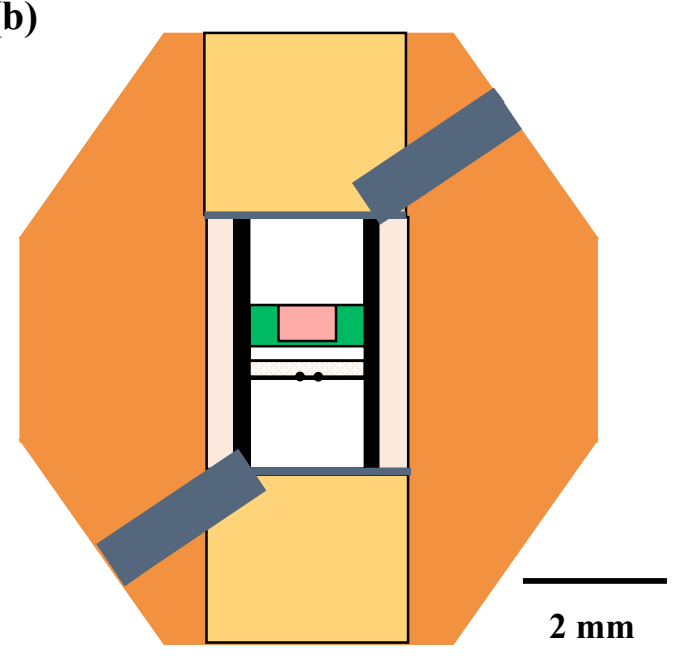

MgO

Graphit

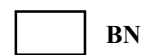

$\mathrm{MgO}+\mathrm{BN}$

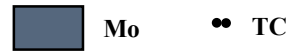

TC

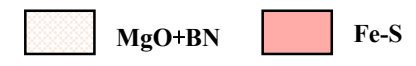

$\mathrm{ZrO}_{2}$

Sapphire

Fig. S1 Schematic illustration of the experimental design. (a) A top view of the diffraction geometry through the gasket and cell assembly. (b) A cross-section of cell assembly used in this study. Temperature was monitored with a $W_{97} R e 3-W_{75} R_{25}$ thermocouple (TC) whose junction was indicated by black dots. 
893

894

895

896

897

898

899

900

901

902

903

904

03
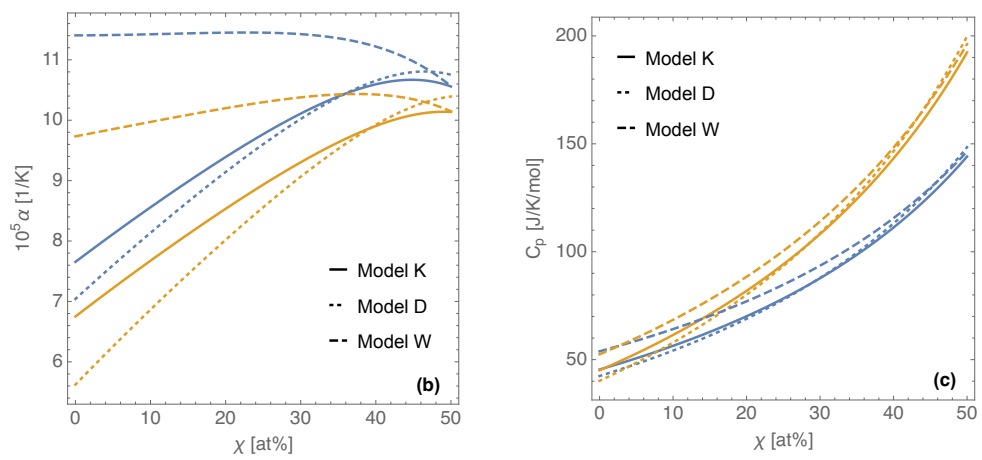

Fig.S2. Density (a), thermal expansivity (b), and iso-baric heat capacity (c) as a function of molar sulfur fraction $\mathrm{X}$ at $5.2 \mathrm{GPa}$ and $10 \mathrm{GPa}$ and $2000 \mathrm{~K}$ for the thermodynamic Model $\mathrm{K}$, Model D and Model W. Model K, Model D and Model W differ in the reference EOS for liquid iron (Model K uses 1-Fe EOS of Komabayashi (2014), Model D uses 1-Fe EOS of Dorogokupets et al. (2017), Model W uses 1-Fe EOS of Wagle and Steinle-Neumann (2019)). Parameters of the thermodynamic models are in Table S1 and S2. 


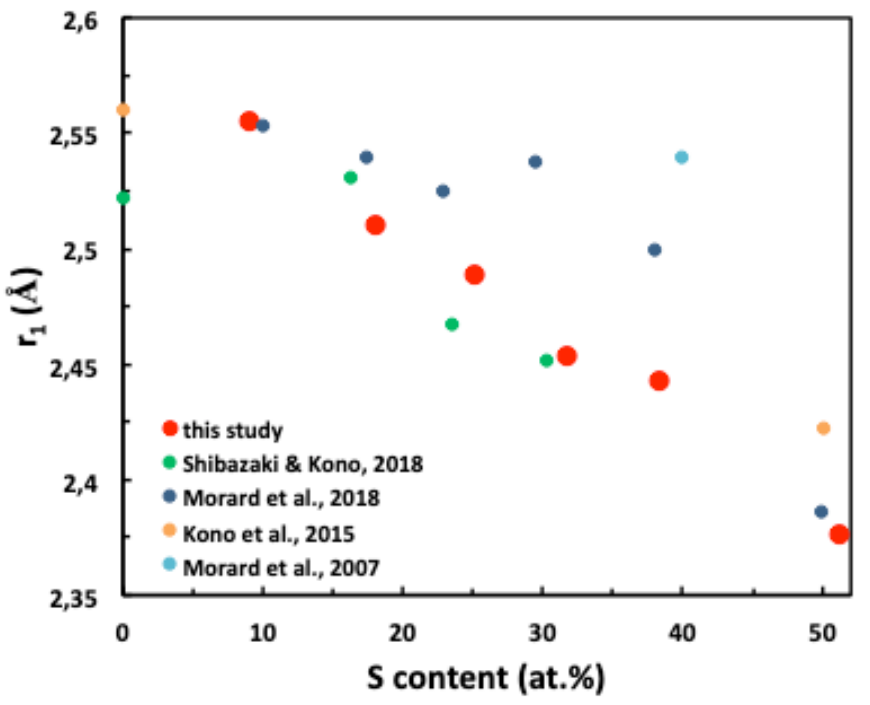

Fig.S3. First peak position $\left(r_{1}\right)$ as a function of the $\mathrm{S}$ content. Previous results from 909 Shibazaki et al. (2018) at 3-5 GPa, Morard et al. (2018) at 2-5 GPa, Kono et al. (2015) at 1-6 $910 \mathrm{GPa}$, and Morard et al. (2007) at 3-17 GPa, were also shown for comparison. For clarity only 911 one value is plotted for each of the considered composition ( $r_{1}$ for a given $\mathrm{S}$ content only 912 moderately depends on pressure and temperature over the P-T range covered by individual 913 studies).

914 

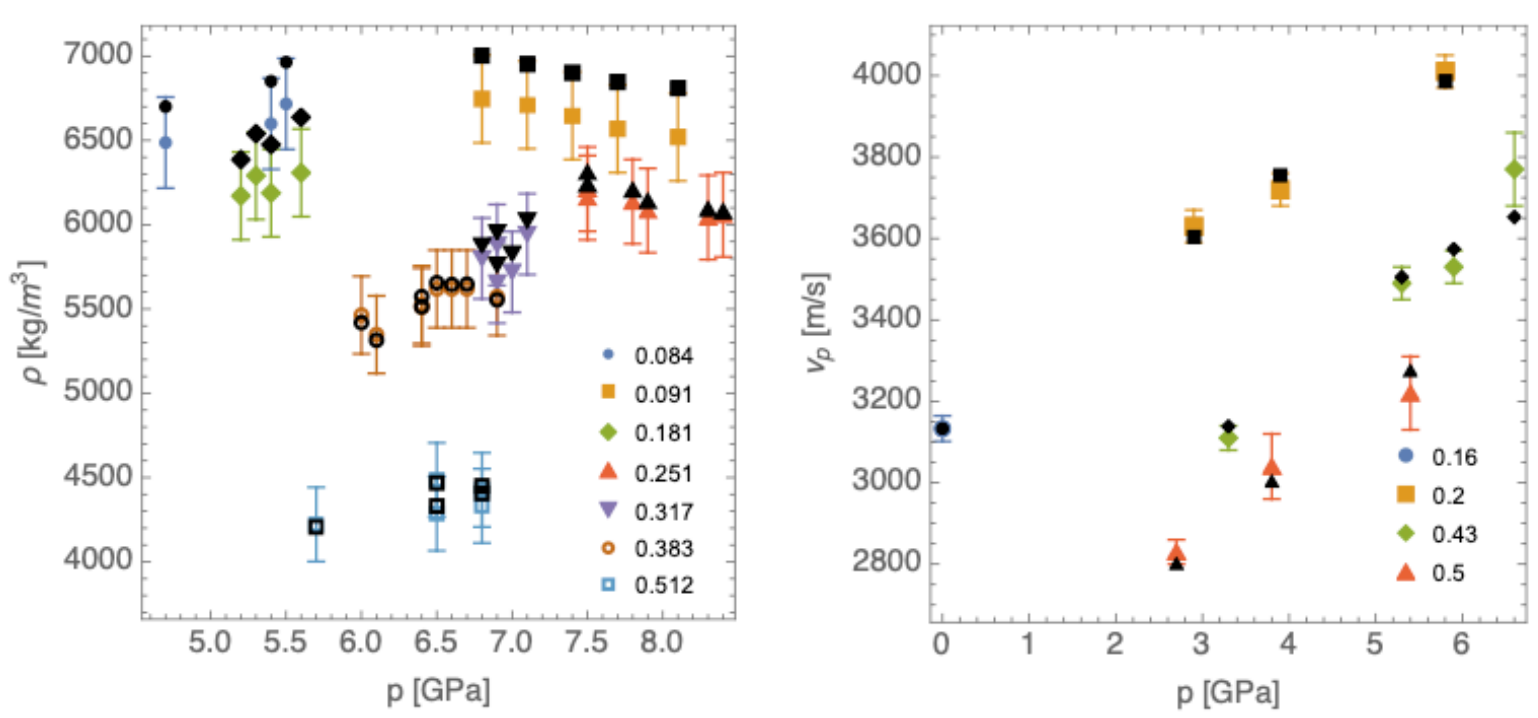

917

918

919

920

Fig. S4. Measured densities (this study) and acoustic velocities (Nasch et al. 1994 and Nishida et al. 2016) (colored symbols) at varying temperature and predicted values according to the thermodynamic Model W (black symbols) under the same condition. Different symbols corresponds to different $\mathrm{S}$ content. For details on the thermodynamic model, please refer to section 2.5 and to Table S1 and S2 for parameters.

925

926 


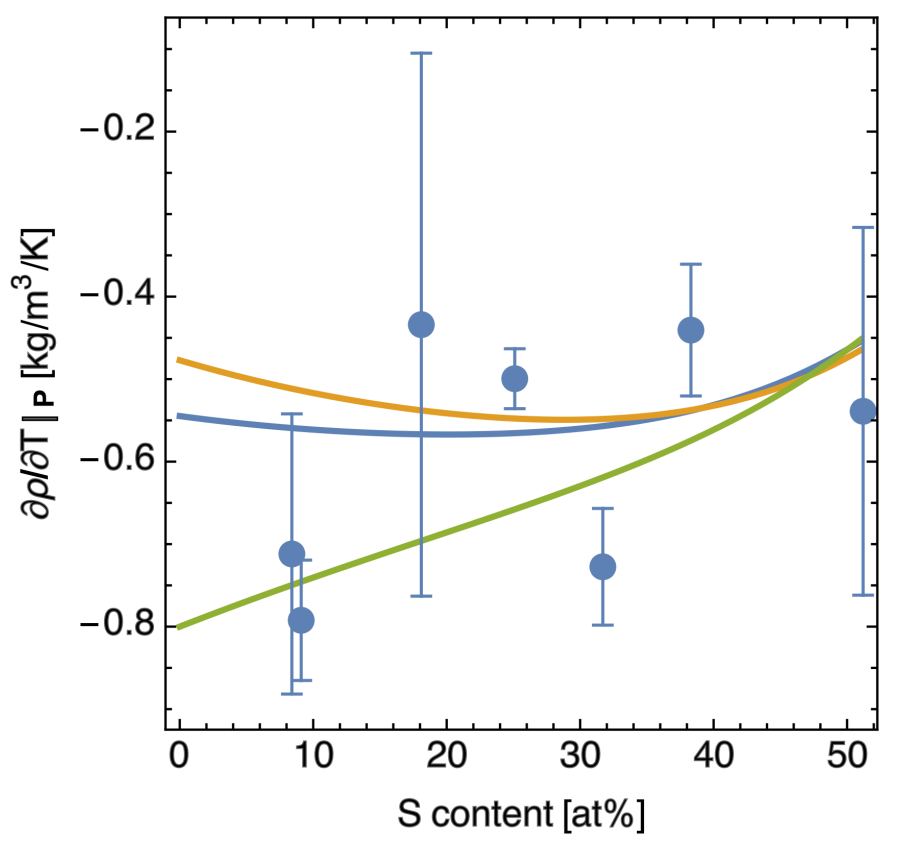

Fig. S5. Temperature derivatives at the constant pressure (7 GPa) of density as a function of $\mathrm{S}$ content. Dots are the slopes of the linear fit to the experimental data (see Fig. 6) with uncertainties at $2 \sigma$. Colored lines are outcomes of thermodynamic Model K (blue), Model D (orange) and Model W (green). Model K, Model D and Model W differ in the reference EOS for liquid iron (Model K uses 1-Fe EOS of Komabayashi (2014), Model D uses 1-Fe EOS of Dorogokupets et al. (2017), Model W uses 1-Fe EOS of Wagle and Steinle-Neumann (2019)). 


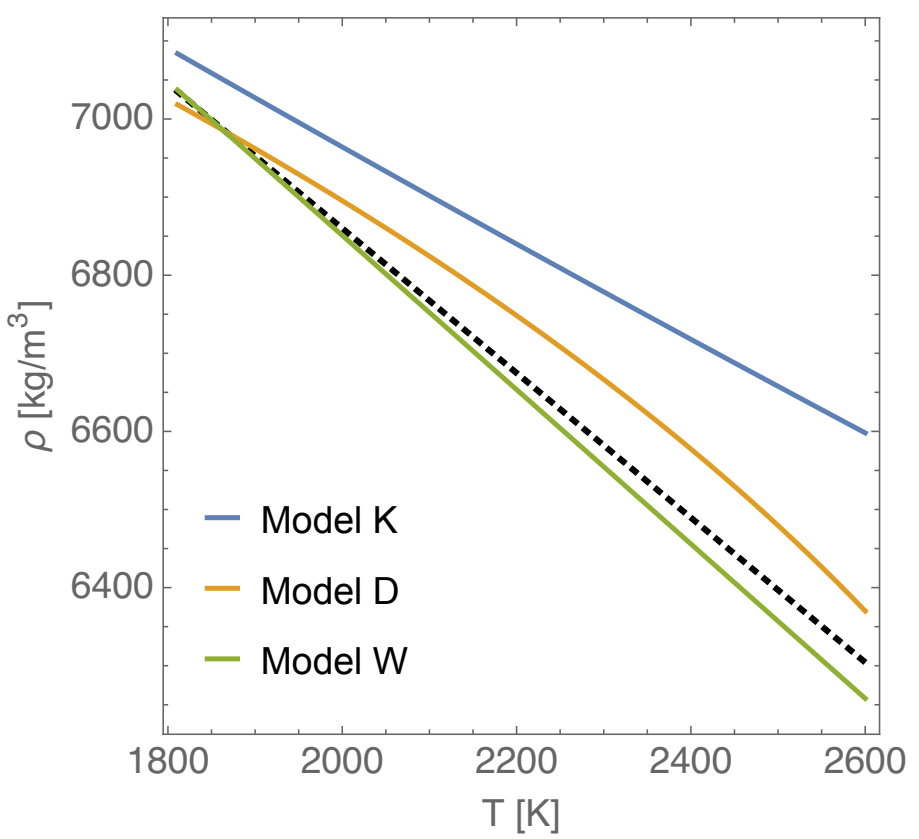

939

940

941

942

Fig. S6. Density as a function of temperature for liquid iron at ambient pressure. Colored 943 lines are outcomes of our thermodynamic models (see section 2.5 and Table S1 and S3 for 944 details). Dashed black line is a fit to data from Assael et al.. (2006), and preferred fit 945 according to Williams (2009).

946 
Table S1. EOS parameters for 1-FeS and Margules parameters estimated from the experimental data of this study and from density measurements of Morad et al. (2018) and acoustic velocities from Nishida et al. (2016) using the EOS of 1-Fe of Komabayashi (2014), Model K, Dorogokupets et al. (2017), Model D and Wagle and Steinle-Neumann (2019),

Model W. $\mathrm{P}_{\mathrm{ref}}=0.1 \mathrm{MPa}, \mathrm{T}_{\mathrm{ref}}=1650 \mathrm{~K}$ and for the $1-\mathrm{FeS}$ end-member $\kappa=1.4$,

$\alpha=11.8 \times 10^{-5} 1 / \mathrm{K}$, and $\mathrm{C}_{\mathrm{p}}=62.5 \mathrm{~J} / \mathrm{K} / \mathrm{mol}$.

954

\begin{tabular}{|c|c|c|c|c|c|c|c|c|c|c|}
\hline $\begin{array}{c}\text { Thermodynamic } \\
\text { model }\end{array}$ & 1-Fe EOS & $\begin{array}{c}V \\
{\left[\mathrm{~cm}^{3} /\right.} \\
\mathrm{mol}]\end{array}$ & $\begin{array}{c}K_{T} \\
{[\mathrm{GPa}]}\end{array}$ & $K_{T}^{\prime}$ & $\gamma$ & $\delta_{T}$ & $W_{F e}$ & $W_{F e S}$ & $\begin{array}{c}B_{0} \\
{[\mathrm{GPa}]}\end{array}$ & $B^{\prime}$ \\
\hline Model K & $\begin{array}{c}\text { Komabayashi } \\
2014\end{array}$ & 24.25 & 13.22 & 6.36 & 0.68 & 0.62 & -9.627 & -3.435 & 3.45 & 2.14 \\
\hline Model D & $\begin{array}{c}\text { Dorogokupets } \\
2017\end{array}$ & 24.26 & 13.12 & 6.38 & 0.68 & 0.52 & -9.481 & -3.528 & 3.44 & 2.10 \\
\hline Model W & Wagle 2019 & 24.26 & 13.07 & 6.44 & 0.68 & 0.61 & -9.627 & -3.393 & 3.44 & 2.23 \\
\hline
\end{tabular}

955

956

957

958

959

960

961

962

963

964

965

966

967

Table S2. Margules parameters required to compute the Fe-S liquidus (see Eq. 9-11 Buono et al. 2011) for the EOS' of 1-Fe of Komabayashi (2014) and Dorogokupets et al. (2017). For the Model W the EOS' of solid Fe from Komabayashi (2014) has been used to compute the slope of the liquidi.

\begin{tabular}{|c|c|c|c|c|c|c|c|}
\hline $\begin{array}{c}\text { Thermodynamic } \\
\text { model }\end{array}$ & 1-Fe EOS & $\begin{array}{c}W_{H, F e} \\
{[\mathrm{~kJ} / \mathrm{mol}]}\end{array}$ & $\begin{array}{c}W_{S, F e} \\
{[\mathrm{~kJ} / \mathrm{mol} / \mathrm{K}]}\end{array}$ & $\begin{array}{c}W_{V, F e} \\
{[\mathrm{~kJ} / \mathrm{mol} /} \\
\mathrm{GPa}]\end{array}$ & $\begin{array}{c}W_{H, F e S} \\
{[\mathrm{~kJ} / \mathrm{mol}]}\end{array}$ & $\begin{array}{c}W_{H, F e S} \\
{[\mathrm{~kJ} / \mathrm{mol} / \mathrm{K}]}\end{array}$ & $\begin{array}{c}W_{H, F e S} \\
{[\mathrm{~kJ} / \mathrm{mol} / \mathrm{G}} \\
\mathrm{Pa}]\end{array}$ \\
\hline Model K & $\begin{array}{c}\text { Komabayashi } \\
2014\end{array}$ & 53.70 & 0.029 & -3.82 & 25.34 & 0.0 & -2.95 \\
\hline Model D & $\begin{array}{c}\text { Dorogokupets } \\
2017\end{array}$ & 69.28 & 0.043 & -2.78 & 27.3 & 0.0 & -3.48 \\
\hline
\end{tabular}

